( 2022 , The Authors. Published by Elsevier Inc. and Fass Inc. on behalf of the American Dairy Science Association ${ }^{\circledR}$. This is an open access article under the CC BY license (http://creativecommons.org/licenses/by/4.0/).

\title{
Fatty acid profile characterization in colostrum, transition milk, and mature milk of primi- and multiparous cows during the first week of lactation
}

\author{
J. N. Wilms, ${ }^{1,2}$ K. S. Hare, ${ }^{1}$ A. J. Fischer-Tlustos, ${ }^{1}$ P. Vahmani, ${ }^{3}$ M. E. R. Dugan, ${ }^{4}$ L. N. Leal, ${ }^{2}$ and M. A. Steele ${ }^{1 *}$ \\ ${ }^{1}$ Department of Animal Biosciences, University of Guelph, Guelph, ON N1G 2W1, Canada \\ ${ }^{2}$ Trouw Nutrition R\&D, 3800 AG Amersfoort, the Netherlands \\ ${ }^{3}$ Department of Animal Science, University of California, Davis 95616 \\ ${ }^{4}$ Agriculture and Agri-Food Canada, Lacombe Research and Development Centre, Lacombe, AB T4L 1V7, Canada
}

\begin{abstract}
The specific fatty acid (FA) profile of colostrum may indicate a biological requirement for neonatal calves. The objective of this study was to characterize the FA profile and yields in colostrum, transition milk, and mature milk in primiparous (PP) and multiparous (MP) cows. Colostrum was milked from $10 \mathrm{PP}$ and 10 MP Holstein cows fed the same pre- and postpartum rations. Milkings (M) 2 to 5 and 12 were respectively termed transition and mature milk. Overall, shortchain FA (C4:0 and $\mathrm{C} 6: 0)$ were 61 and $50 \%$ lower in colostrum than mature milk, respectively. A parity by milking interaction was also present, with higher C4:0 for PP cows at M2 and for MP cows at M12. Additionally, higher concentrations of $\mathrm{C} 6: 0$ were present for PP cows at M2 through M4 and for MP cows at M12. Palmitic (C16:0) and myristic (C14:0) acids were $16 \%$ and $27 \%$ higher in colostrum than mature milk, respectively. However, total saturated FA remained relatively stable. Branched-chain FA were $13 \%$ lower in colostrum than mature milk and higher in PP than MP cows throughout the milking period. The proportion of trans-monounsaturated FA (MUFA) was $42 \%$ higher in $\mathrm{PP}$ cows throughout the milking period, as well as $15 \%$ lower in colostrum than mature milk. In contrast, cisMUFA and total MUFA were not affected by milking nor parity. Linoleic acid (LA) was 13\% higher in colostrum than transition and mature milks, but $\alpha$-linolenic acid (ALA) did not differ. Consequently, the ratio of LA to ALA was $23 \%$ higher in colostrum than mature milk and 25\% higher in MP cows. Linoleic acid was also $13 \%$ higher in MP cows, whereas ALA was $15 \%$ higher in PP cows. Conjugated linoleic acid (CLA, cis-9,trans-11) was $63 \%$ higher in PP cows, and no dif-
\end{abstract}

Received June 15, 2021.

Accepted November 12, 2021.

*Corresponding author: masteele@uoguelph.ca ferences between colostrum and mature milk were detected. Overall, polyunsaturated FA (PUFA) from the n- 6 and n-3 series were over $25 \%$ higher in colostrum compared with transition and mature milk. Milking by parity interactions were present for arachidonic acid (ARA), eicosapentaenoic acid (EPA), docosapentaenoic acid (DPA), docosahexaenoic acid (DHA), and total n-3 PUFA, translating to higher proportions in PP cows in M1 to M3, whereas proportions remained relatively stable throughout the milking period in MP cows. Despite increasing milk yields throughout the subsequent milkings, higher yields of EPA, ARA, DPA, and DHA were present in colostrum than in mature milk. Greater proportions and yields of n- 3 and n- 6 FA in colostrum may translate to specific requirements for newborn calves. Differences were also observed between PP and MP cows and may reflect different nutrient requirements and partitioning.

Key words: colostrum, fatty acids, transition milk, whole milk, Holstein

\section{INTRODUCTION}

With more than 400 different fatty acids (FA), milk fat is the most complex natural fat and is also the most variable macronutrient in milk (Jensen et al., 1991; Lindmark Månsson, 2008; Moltó-Puigmartí et al., 2011). Fat from mature milk is almost exclusively present in the form of triglycerides $(\sim 98 \%$; Taylor and MacGibbon, 2002), consisting of a glycerol backbone to which 3 FA following a stereo-specific numbering position are attached (Lammi-Keefe and Jensen, 1984). Milk fat provides $\sim 50 \%$ of the total dietary energy, as well as essential FA, presenting important structural and metabolic functions to newborn animals (Delplanque et al., 2015; Grote et al., 2016). The FA profile of milk fat derives from dietary FA, ruminal biohydrogenation, and mammary lipogenesis (Wiking et al., 2004; McFadden and Corl, 2009). Other factors, such as breed (Poulsen et al., 2012), parity, stage of lacta- 
tion (O'Callaghan et al., 2020), and feeding practices (Moate et al., 2007), are also known to influence the FA profile of bovine milk.

Parturition is characterized by metabolic transitions that largely modulate the FA profile of colostrum and transition milk. For instance, increased feed intake following calving increases volatile $\mathrm{FA}$ production from microbial fermentation in the rumen, serving as substrate for de novo FA synthesis in the mammary gland (Laliotis et al., 2010; Woolpert et al., 2017). Additionally, it is not uncommon for up to $40 \mathrm{~kg}$ of body fat to be mobilized within the first few weeks around calving for modern high-producing cows, resulting in an increased proportion of preformed FA ( $>18$ carbon atoms) in milk (Bell, 1995; Gross et al., 2011; Daniel et al., 2018). In this context, differences between primiparous and multiparous cows, having different energy requirements, should also be considered.

Bovine colostrum supports the health and welfare of young calves by providing essential bioactives and immune factors (Blum and Hammon, 2000; Godden, 2008). Although the protein fraction of colostrum and its immune components have been extensively studied in the first days following parturition (Nissen et al., 2017; Fahey et al., 2020; Honan et al., 2020), knowledge related to the changes occurring in relation to fat composition is limited. From a teleological stance, elevated concentrations and yields of certain FA in colostrum, compared with transition and mature milk, may indicate a biological need of the neonatal calf. Previous bovine colostrum research has demonstrated an effect of days post-parturition on the FA profile of colostrum, transition milk, and mature milk (Contarini et al., 2014; O'Callaghan et al., 2020). Colostrum is rich in lipid molecules essential for newborns, including elevated concentrations of n-3 PUFA, palmitic acid (C16:0), phospholipids, and cholesterol (Noble et al., 1978; Contarini et al., 2014; O'Callaghan et al., 2020). In contrast, lower concentrations of trans-FA were detected in colostrum compared with mature milk (Contarini et al., 2014). These specificities of colostrum fat composition have also been observed in human colostrum (Moltó-Puigmartí et al., 2011; Floris et al., 2020; Ramiro-Cortijo et al., 2020).

Developing knowledge regarding milk composition during the early stage of lactation can improve our understanding of the physiology of the dairy cow and the needs of neonatal calves. The hypothesis of this experiment was that colostrum would have a distinct FA composition compared with transition milk and mature milk. The objective of the study was to characterize the FA profile of colostrum, transition milk, and mature milk in primi- and multiparous Holstein cows fed the same diets pre- and postpartum.

\section{MATERIALS AND METHODS}

This study was conducted at Breevliet Farms Ltd. (Millet, AB, Canada) between May and June 2017. All procedures described in this article complied with the Canadian Council of Animal Care (CCAC, 1993) and the University of Alberta Animal Care and Use Committee for Livestock (AUP 00002015).

\section{Experimental Design and Measurements}

Companion papers (Fahey et al., 2020; FischerTlustos et al., 2020; Honan et al., 2020) provide details on animal husbandry and experimental design, and, as such, the present study will describe these aspects in brief. Primiparous $(\mathbf{P P}, \mathrm{n}=10)$ and multiparous $(\mathbf{M P}, \mathrm{n}=10)$ Holstein cows were enrolled in the study at calving. Multiparous cows [median parity of 3 (25th quartile $=2,75$ th quartile $=6$ ); dry period length: $53.4 \pm 3.8 \mathrm{~d}]$ were dried off from their previous lactation using Spectramast DC (Zoetis). After calving, cows were group-housed and milked twice daily at 0500 and $1600 \mathrm{~h}$. No cows displayed clinical signs of illness or received antibiotics during the 6-d sampling period. Homogeneous colostrum and milk samples $(2 \times 15 \mathrm{~mL})$ were collected from the milking system (BouMatic) over the first 7 DIM. The colostrum sample was collected at the first milking (M1) following parturition $(5.3 \pm 0.7 \mathrm{~h}$ after parturition). Time intervals between M1 and subsequent milkings were $12.0 \pm 0.3 \mathrm{~h}$. The 12th milking was thus sampled $6 \mathrm{~d}(137 \pm 0.8 \mathrm{~h})$ after calving. Milkings 2 to 5 (M2-5) and milking 12 (M12) were respectively termed transition and mature milk (Blum and Hammon, 2000). Yield at each milking was recorded, and samples were immediately snap-frozen in liquid nitrogen and transferred to $-20^{\circ} \mathrm{C}$ storage until analysis.

\section{Diets and Feeding}

All cattle were fed the same close-up (3 wk prepartum) and fresh rations described in Fischer-Tlustos et al. (2020). In brief, the close-up diet included $53.2 \%$ barley silage, $17.8 \%$ brewers grain, $24.1 \%$ barley straw, and $5.0 \%$ dry cow supplement. The lactation ration included $12.1 \%$ barley silage, $17.6 \%$ corn silage, $19.5 \%$ corn silage, $3.5 \%$ brewers grain, $11.6 \%$ haylage, $12.1 \%$ corn distiller, $8.4 \%$ alfalfa hay, $0.7 \%$ palm fat, and $14.5 \%$ lactating cow supplement.

\section{Fatty Acid Analyses}

Total lipids were extracted from milk or colostrum according to the method developed by Feng et al. (2004) 
with modifications. Briefly, 5 to $10 \mathrm{~mL}$ of colostrum or milk was centrifuged at $15,000 \times g$ for $30 \mathrm{~min}$ at $4^{\circ} \mathrm{C}$. The fat-cake layer was transferred to a $1.5-\mathrm{mL}$ microtube and incubated at room temperature for $20 \mathrm{~min}$, followed by incubation in a heating block at $37^{\circ} \mathrm{C}$ for 2 min. Thereafter, samples were centrifuged at 19,300 $\times$ $g$ for 20 min at $22^{\circ} \mathrm{C}$ using a microcentrifuge (Centrifuge 5415 D, Eppendorf) and placed in a heating block maintained at $45^{\circ} \mathrm{C}$ to allow for fat separation. Then, the top layer of lipid $(\sim 25 \mathrm{mg})$ was collected, weighed, and stored at $-80^{\circ} \mathrm{C}$ and sent to the Lacombe Research and Development Centre (Agriculture and Agri-Food Canada, Lacombe, AB, Canada). Samples were then thawed, freeze-dried, and direct-methylated with sodium methoxide according to Dugan et al. (2007). Fatty acid composition was determined via gas-liquid chromatography based on a method described by Kramer et al. (2008). Gas-liquid chromatography was performed on a CP-3800 GC equipped with a flame-ionization detector, autosampler, a split/splitless injector and a CPSil88 column (100 m, 25- $\mu \mathrm{m}$ internal diameter, 0.2- $\mu \mathrm{m}$ film thickness). Hydrogen was used as the carrier gas $(1 \mathrm{~mL} / \mathrm{min}$ initial flow rate, head pressure $25 \mathrm{psi})$, and the injection port was set at $250^{\circ} \mathrm{C}$, with the detector set at $260^{\circ} \mathrm{C}$. The temperature program was as follows: initial temperature at $45^{\circ} \mathrm{C}$ for $4 \mathrm{~min}$, raised to $175^{\circ} \mathrm{C}$ at a rate of $13^{\circ} \mathrm{C} / \mathrm{min}$, and held for $27 \mathrm{~min}$, then raised to $215^{\circ} \mathrm{C}$ at a rate of $4.0^{\circ} \mathrm{C} / \mathrm{min}$, and finally held at this temperature for $35 \mathrm{~min}$ (Kramer et al., 2008). For each GC analysis, $1 \mu \mathrm{L}$ of sample was injected and a 20:1 split was used. Individual peaks were identified using reference standards (GLC463, GLC-603, and UC-59M, $\mathrm{Nu}$-Chek Prep Inc.) and according to the peak order and retention times reported in the literature (CruzHernandez et al., 2004; Kramer et al., 2008). Shortchain FAME were corrected for mass discrepancy based on the theoretical response factors defined by Wolff et al. (1995).

\section{Statistical Analysis}

The sample size of the experiment was selected for the original purpose of the study, which was to detect a difference between parity in colostrum and milk oligosaccharide concentrations, as described by FischerTlustos et al. (2020).

All variables were analyzed as repeated measurements using PROC GLIMMIX (SAS/STAT 9.4; SAS Institute Inc., 2018). The statistical model for the FA profile (\% total FA) and FA yields (g/d) included the fixed effects of parity, milking, and the interaction between milking and parity. Milking was treated as a repeated measurement, to model the autocorrelation between multiple measurements conducted on one experimental unit. Cows were blocked by the time interval relative to their first milking, to account for the influence of lag on colostrum FA composition. Cow and the milking by block interaction were included as random effects within the model:

$$
\mathrm{Y}_{\mathrm{hij}}=\mu+\mathrm{M}_{\mathrm{i}}+\mathrm{P}_{\mathrm{j}}+\mathrm{MP}_{\mathrm{ij}}+\mathrm{MB}_{\mathrm{hi}}+\varepsilon_{\mathrm{hij}},
$$

where $Y_{\text {hij }}$ is the dependent variable; $\mu$ is the overall mean; $\mathrm{M}_{\mathrm{i}}$ is the fixed effect of the ith milking; $\mathrm{P}_{\mathrm{j}}$ is the fixed effect of the jth parity; $\mathrm{MP}_{\mathrm{ij}}$ is the fixed effect of the interaction between the ith milking and the jth parity; $\mathrm{MB}_{\mathrm{hi}}$ is the random effect of the interaction between the hth block and the ith milking; and $\varepsilon_{\text {hij }}$ the random error associated with the hth block at the ith milking with the jth parity. At least 4 variance-covariance structures suitable for use with unequally spaced measurements were evaluated. These included the variance components, compound symmetry, ante-dependence, unstructured, and heterogeneous compound symmetry. The covariance structure allowing the lowest Schwarz's Bayesian information criterion was selected. Data were confirmed as normally, independently, and identically distributed using PROC UNIVARIATE (Shapiro-Wilk $P>0.05$ ) and the COVTEST statement (Gen. ChiSq. $>0.05)$ in PROC GLIMMIX. When data were nonidentically distributed between primiparous and multiparous cattle, heteroscedasticity was controlled using the GROUP statement within PROC GLIMMIX. Significant differences were declared at $P<0.05$. When considering the effect of milking, only significant differences between colostrum, transition milk, and mature milk are described.

Principal component analysis (PCA) is a mathematical procedure reducing data dimensionality while retaining most of the variation in a data set (Ringnér, 2008). This approach enables visual assessment of similarities and differences between samples, bringing complementary information to the statistical model presented herein, which would otherwise only allow for observation of single FA. This analysis was performed using the PCA tool in OriginPro (OriginLab Corp., 2021). All FA presented in Figure 1 were considered for this analysis.

\section{RESULTS}

\section{Milk Yield and Milk Fat Yield}

Results for milk yield and milk composition are described in Fischer-Tlustos et al. (2020). In brief, MP cows had a $27 \%$ greater milk yield per milking over the first 7 DIM $(P<0.001)$. Milk yield was higher in M4 onward, compared with colostrum and M2, with 


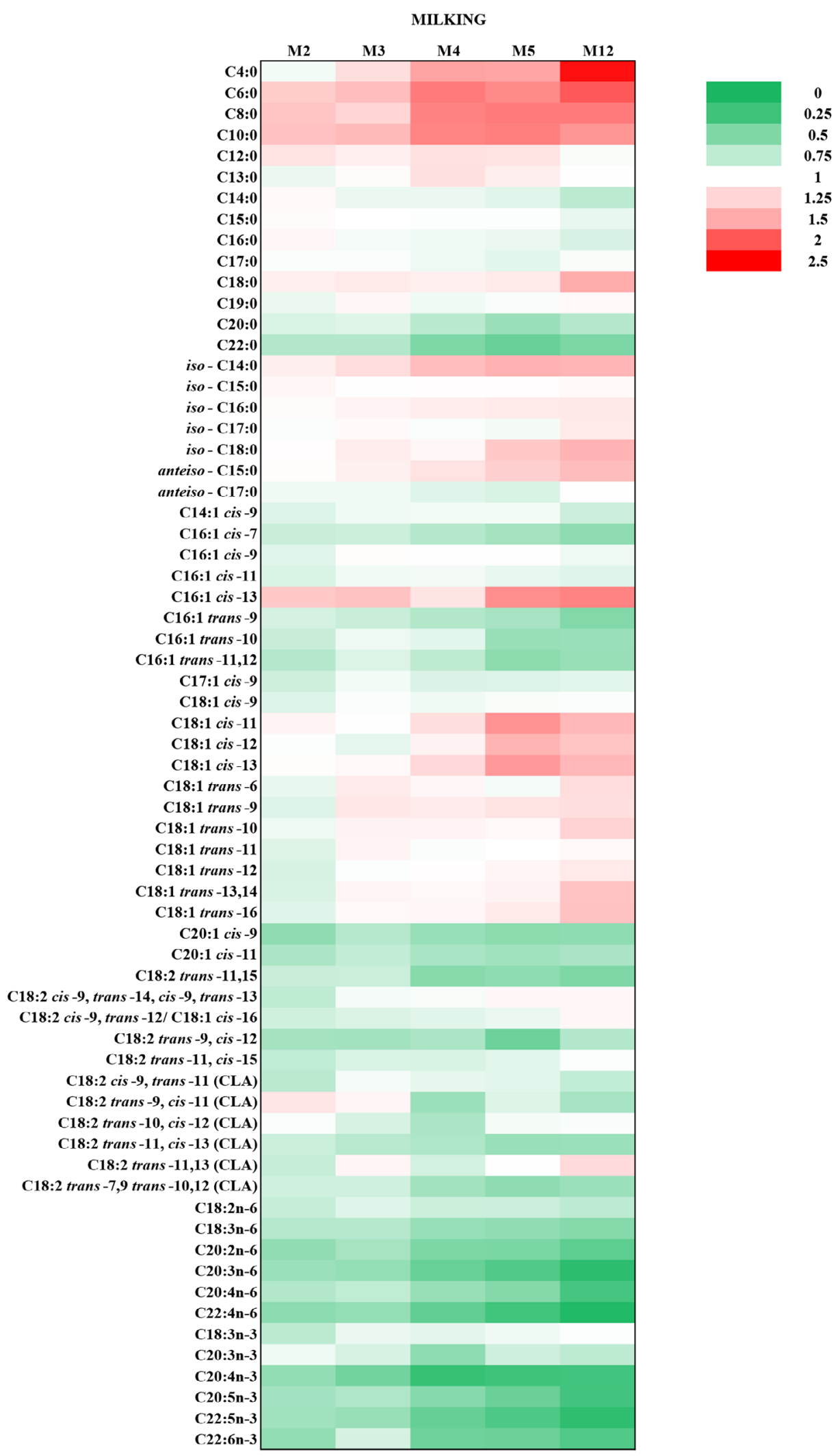

Figure 1. Heatmap displaying the fold change difference of individual fatty acids in relation to the fatty acid profile of colostrum (M1). Individual values are differentiated by a color contrast going from green (fatty acid percentage decreases from colostrum) to red (fatty acid percentage increases from colostrum). 
Wilms et al.: FATTY ACID PROFILES IN BOVINE MILK

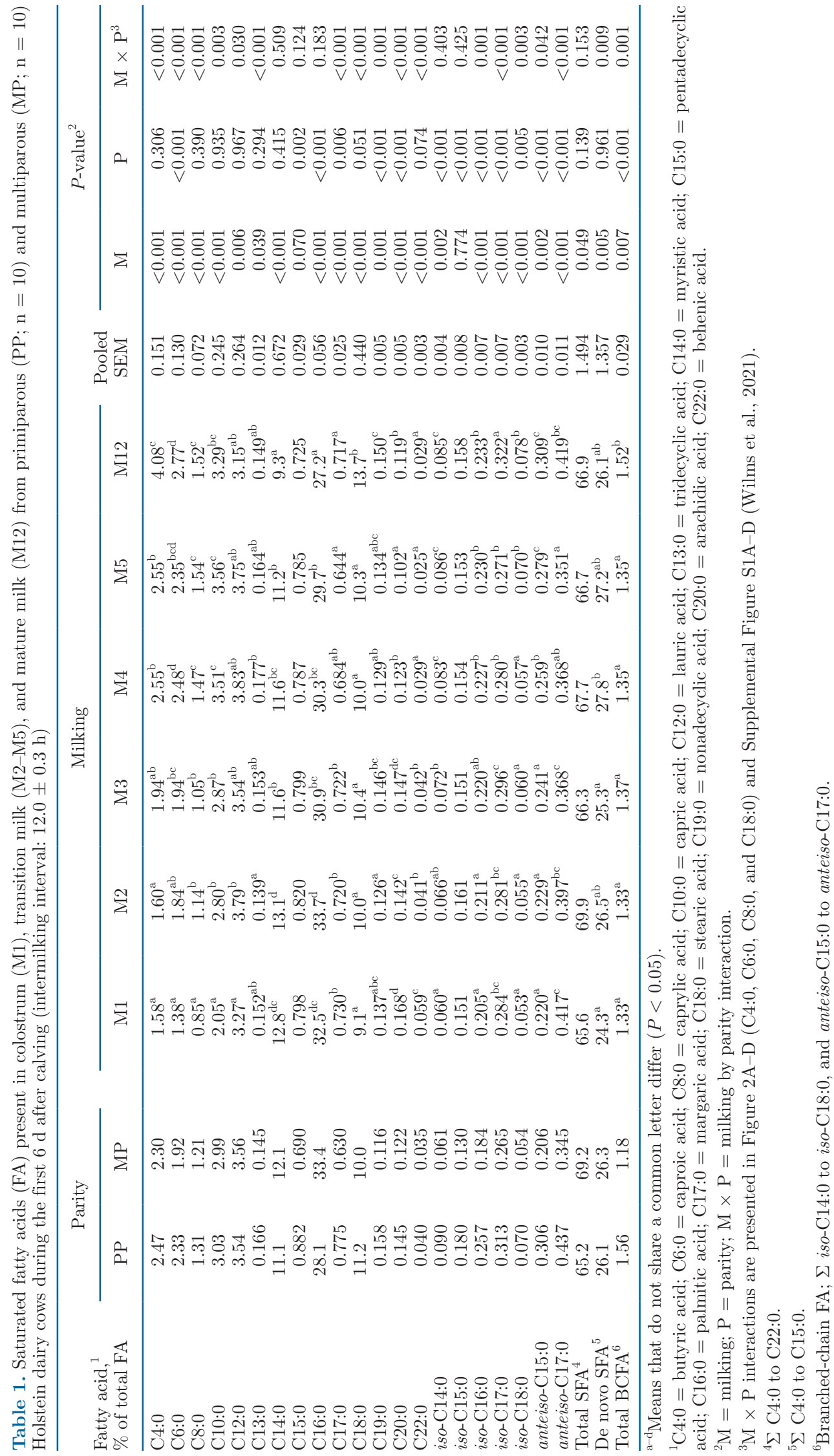




\section{A}
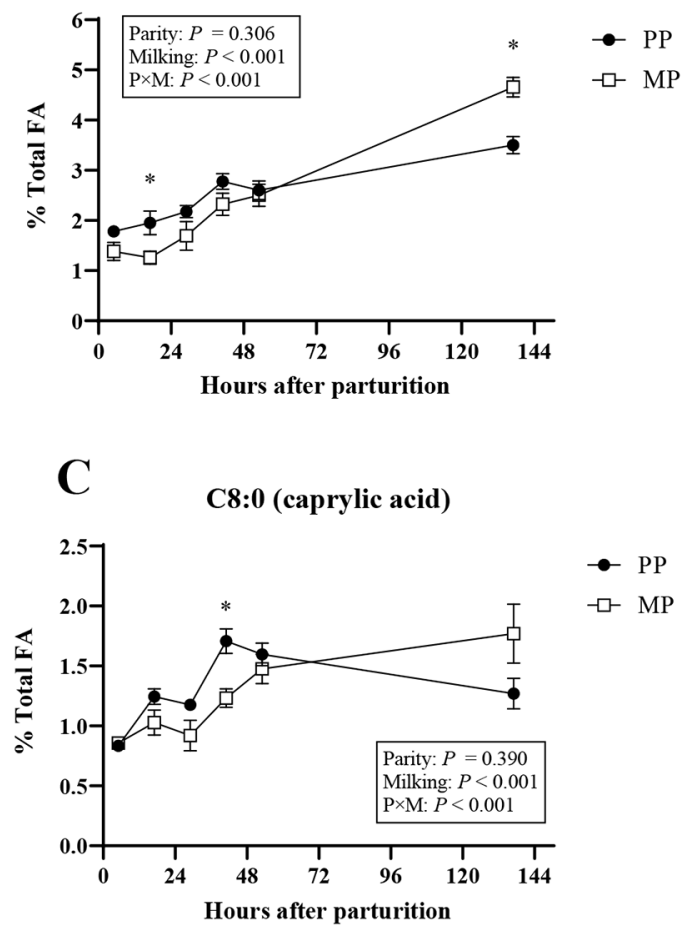

B

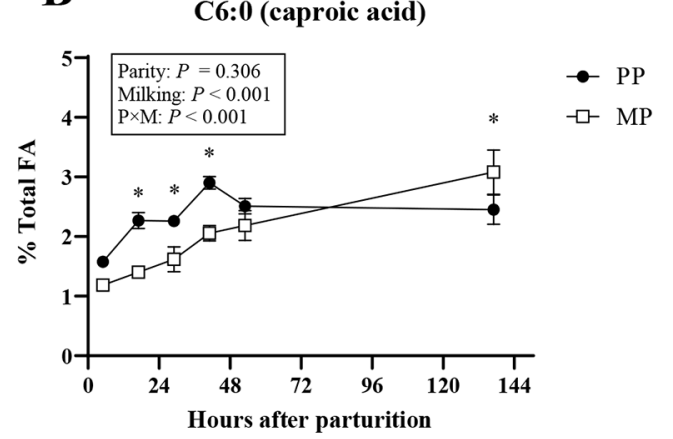

D

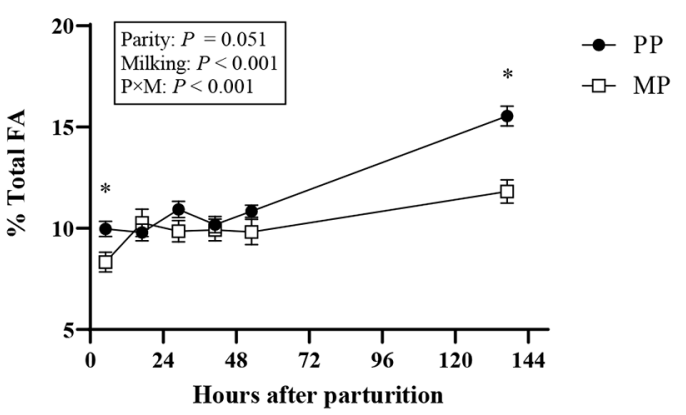

Figure 2. Saturated fatty acids (FA), including C4:0 (A), C6:0 (B), C8:0 (C), and C18:0 (D) from colostrum, transition, and mature milks of primiparous $(\mathrm{PP} ; \mathrm{n}=10)$ and multiparous Holstein dairy cows (MP; $\mathrm{n}=10)$ during the first week of lactation. Data are presented as LSM and SEM. Significant interactions between milking $(\mathrm{M})$ and parity $(\mathrm{P})$ at each time point are indicated by $*(P \leq 0.05)$.

MP cows having a greater yield than PP cows in M10, M12, and M14 $(P<0.001)$. Fat percentage was $27 \%$ higher in PP cows $(P=0.002)$, whereas fat yield was $16 \%$ higher in MP cows over the first 7 DIM $(P=0.03)$. Fat percentage was the highest in colostrum compared with all other milkings $(P<0.001)$ and was also higher in colostrum and M2 of PP and MP cows $(P<0.001)$. In contrast, fat yield was lower in colostrum and M2 to M3 compared with M6 onward $(P<0.001)$. Additionally, PP cows had a higher fat yield in colostrum and a lower fat yield in M10 compared with MP cows ( $P$ $<0.001)$.

\section{Saturated Fatty Acid Profile}

Parity affected ( $P \leq 0.006$; Table 1) C6:0, C15:0, C16:0, C17:0, C19:0, and C20:0 concentrations. Primiparous cows had higher proportions of these FA, except for C16:0, which was present at a lower concentration in PP than MP milk (28.1 vs. $33.4 \%$ FA, respectively). Apart from C15:0 and iso-C15:0, the proportions of all individual SFA changed $(P \leq 0.039)$ with respect to milking. The short-chain FA (SCFA) C4:0 and C6:0 were 61 and $50 \%$ lower $(P<0.001)$ in colostrum than mature milk, respectively. Milk C4:0 remained at low concentrations from M2 to M5 relative to M12. The observed differences in SCFA for each milking relative to colostrum are illustrated in Figure 1. Overall, proportions of SCFA increased with milking period; however, milking by parity interactions $(P<0.001)$ indicated differing patterns of increase. For both C4:0 and $\mathrm{C} 6: 0$, proportions were higher in transition milk in PP cows and higher for MP cows in mature milk. Milk C4:0 proportions were greater in $\mathrm{PP}$ cows at M2 and in MP cows at M12. Similarly, milk C6:0 proportions were greater in $\mathrm{PP}$ than MP cows at M2 to M4 and in MP cows at M12 (Figure 2A and 2B). Similar patterns were observed for $\mathrm{C} 8: 0$, where greater proportions of C8:0 were present in milk from PP cows at M4 (Figure 2C; $P<0.001)$. Palmitic (C16:0) and myristic acids (C14:0) were $13 \%$ and $27 \%$ higher $(P<0.001)$ in colostrum than in mature milk, respectively. Additionally, C20:0 and C22:0 concentrations were respectively $29 \%$ and $51 \%$ higher $(P<0.001)$ in colostrum than mature milk. Branched-chain FA (BCFA) were $11 \%$ lower $(P$ $\leq 0.002$ ) in colostrum and transition milk than mature milk, and higher $(P \leq 0.005)$ in milk from PP than MP cows throughout the milking period (Supplemen- 
tal Figure S1D; https://figshare.com/articles/figure/ Wilms_et_al_2022_FA_characterization_in_colostrum _transition_milk_and_mature_milk_Supplemental _material_docx/17277938, Wilms et al., 2021). The total proportion of SFA did not differ $(P=0.14)$ between colostrum, transition milk, or mature milk but was $6 \%$ higher $(P=0.049)$ in milk produced by MP rather than PP cows. Interactions between milking and parity $(P \leq$ 0.042) were present for all SFA, with the exceptions of $\mathrm{C} 14: 0$ to $\mathrm{C} 16: 0$, iso-C14:0, and iso-C15:0. Interactions between milking and parity resulted in higher proportions of C17:0 (Supplemental Figure S1A), C18:0 (Figure 2D), C19:0 (Supplemental Figure S1B), and C20:0 (Supplemental Figure S1C) in PP than MP cows at M12 $(P \leq 0.001)$. Additionally, higher proportions of C17:0, C18:0, C19:0, and C20:0 were present in colostrum of PP compared with MP cows. Some transition milk samples also showed higher FA proportions in PP than MP cows; M3 and M5 for C17:0, M2 to M3 and M5 for C19:0, and M3 and M5 for C20:0.

\section{Monounsaturated Fatty Acid Profile}

A higher $(P<0.001$; Table 2 ; Supplemental Figure S2A; https://figshare.com/articles/figure/Wilms _et_al_2022_FA_characterization_in_colostrum _transition_milk_and_mature_milk_Supplemental _material_docx/17277938, Wilms et al., 2021) proportion of trans-C16:1 and lower proportion $(P=0.019)$ of cis-C16:1 were found in milk from PP cows. Colostrum differed $(P<0.001)$ from transition and mature milk, having an approximately $30 \%$ higher concentration of trans-C16:1. Parity effects $(P \leq 0.006)$ were present for all trans-C18:1, except $\mathrm{C} 18: 1$ trans-10 $(P=0.27)$; thus, parity affected $(P<0.001)$ the total proportion of trans-C18:1 produced (Supplemental Figure S2B). Trans-C18:1 was $16 \%$ lower $(P<0.001)$ in colostrum than mature milk. Parity did not affect $(P \geq 0.43)$ the proportions of most cis-C18:1 FA, although the proportion of $\mathrm{C} 18: 1$ cis-11 was greater $(P=0.005)$ in milk produced by $\mathrm{PP}$ rather than MP cows. The proportions of $\mathrm{C} 18: 1$ cis-11, C18:1 cis-12, and $\mathrm{C} 18: 1$ cis-13 were lower $(P<0.001)$ in colostrum than mature milk. The total percentage of cis-C18:1 was not affected $(P \geq$ $0.055)$ by parity nor milking. The proportional sum of cis-C20:1 was $30 \%$ higher $(P<0.001)$ in milk from PP compared with MP cows and $36 \%$ higher $(P<0.001)$ in colostrum than mature milk. The proportion of transMUFA was $42 \%$ higher $(P<0.001)$ in milk from PP cows and $15 \%$ lower $(P<0.001$; Supplemental Figure $\mathrm{S} 2 \mathrm{C}$ ) in colostrum than mature milk. For trans-C16:1, trans-C18:1, and trans-MUFA, higher proportions were detected in milk from PP than MP cows throughout the milking period.

\section{Polyunsaturated Fatty Acid Profile}

Conjugated linoleic acid (CLA, cis-9,trans-11) was $63 \%$ higher $(P=0.005$; Table 3$)$ in milk from PP cows, and no differences between colostrum, transition, and mature milk were detected. Linoleic acid (LA) was 13\% higher $(P=0.044)$ in milk from MP cows, whereas $\alpha$-linolenic acid (ALA, C18:3n-3) was $15 \%$ higher ( $P$ $=0.034)$ in milk from PP cows. Proportions of LA and arachidonic acid $($ ARA $)$ were higher $(P<0.001)$ in colostrum than transition milk, and the proportions of LA and ARA in whole milk were lower than those in transition milk. Primiparous cows produced milk that contained larger $(P<0.001)$ proportions of ARA, eicosapentaenoic acid (EPA), docosahexaenoic acid (DHA), and docosapentaenoic acid (DPA) than milk from MP cows. Proportions of ARA, EPA, and DPA were higher $(P<0.001)$ in colostrum than transition milk, and in transition milk than whole milk. The interaction between milking and parity indicated greater $(P$ $\leq 0.01$; Figure $3 \mathrm{~A}-\mathrm{D}$ ) proportions of ARA (M1-3 and M12), EPA (M1-3, M5, and M12), and DPA (M1-3, $\mathrm{M} 5$, and M12) were produced in milk from PP cows. The proportion of DHA was higher in colostrum than mature milk $(P=0.005)$. A milking by parity interaction showed higher DHA concentrations in PP cows in M1 through M3 $(P=0.023$; Figure 3.D). The n-3 PUFA were $25 \%$ higher $(P<0.001)$ in milk produced by PP cows and were affected $(P=0.012)$ by interaction between parity and milking. Overall, n-6 and n-3 PUFA were elevated $(P \leq 0.029)$ by at least $25 \%$ in colostrum compared with transition and mature milk. However, transition and mature milk did not differ for n-3 PUFA or n-6 PUFA. Interactions between milking and parity were present $(P<0.001$; Figure $3 \mathrm{D})$ from M1 to M3, showing higher proportions of n-3 PUFA in milk from PP cows relative to MP cows. The ratio of n-6 to n-3 PUFA was $28 \%$ higher $(P<0.001)$ in MP compared with PP cows.

\section{Fatty Acid Yields}

Short-chain FA and C8:0 yields did not differ $(P \geq$ 0.18 ; Table 4) between parities, but higher yields $(P$ $<0.001)$ were produced at M12 relative to M1. However, the parity by milking interaction translated to higher yields of C4:0 for PP cows at M2 and MP cows at M12 $(P=0.003$; Supplemental Figure S3A; https: / / figshare.com/articles/figure/Wilms_et_al_2022 _FA_characterization_in_colostrum_transition_milk _and_mature_milk_Supplemental_material_docx/ 17277938, Wilms et al., 2021). Similarly, results showed higher yields of C6:0 for PP cows at M2 to M3 and for MP cows at M12 $(P=0.005$; Supplemental Figure 
Wilms et al.: FATTY ACID PROFILES IN BOVINE MILK

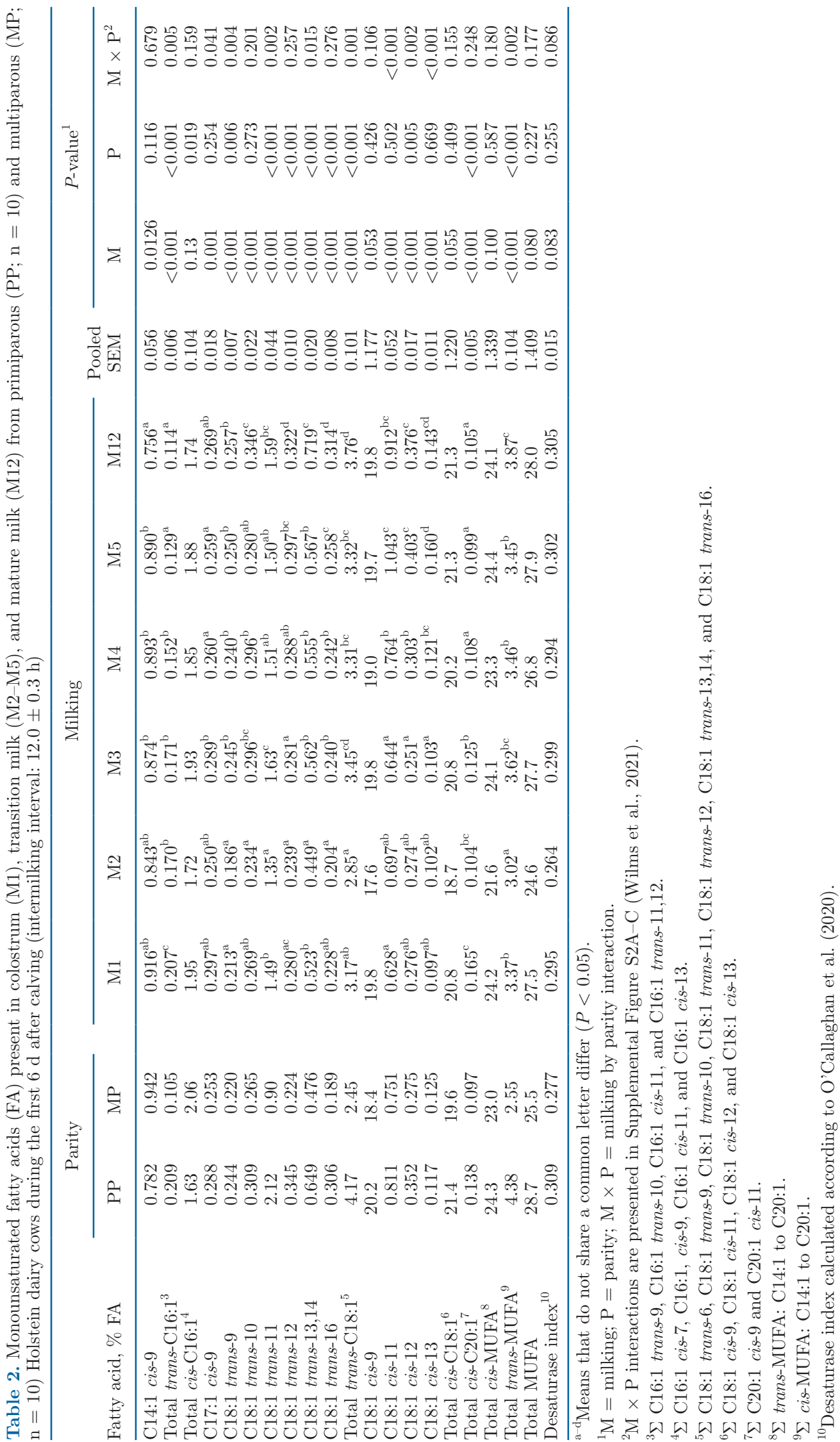


Wilms et al.: FATTY ACID PROFILES IN BOVINE MILK

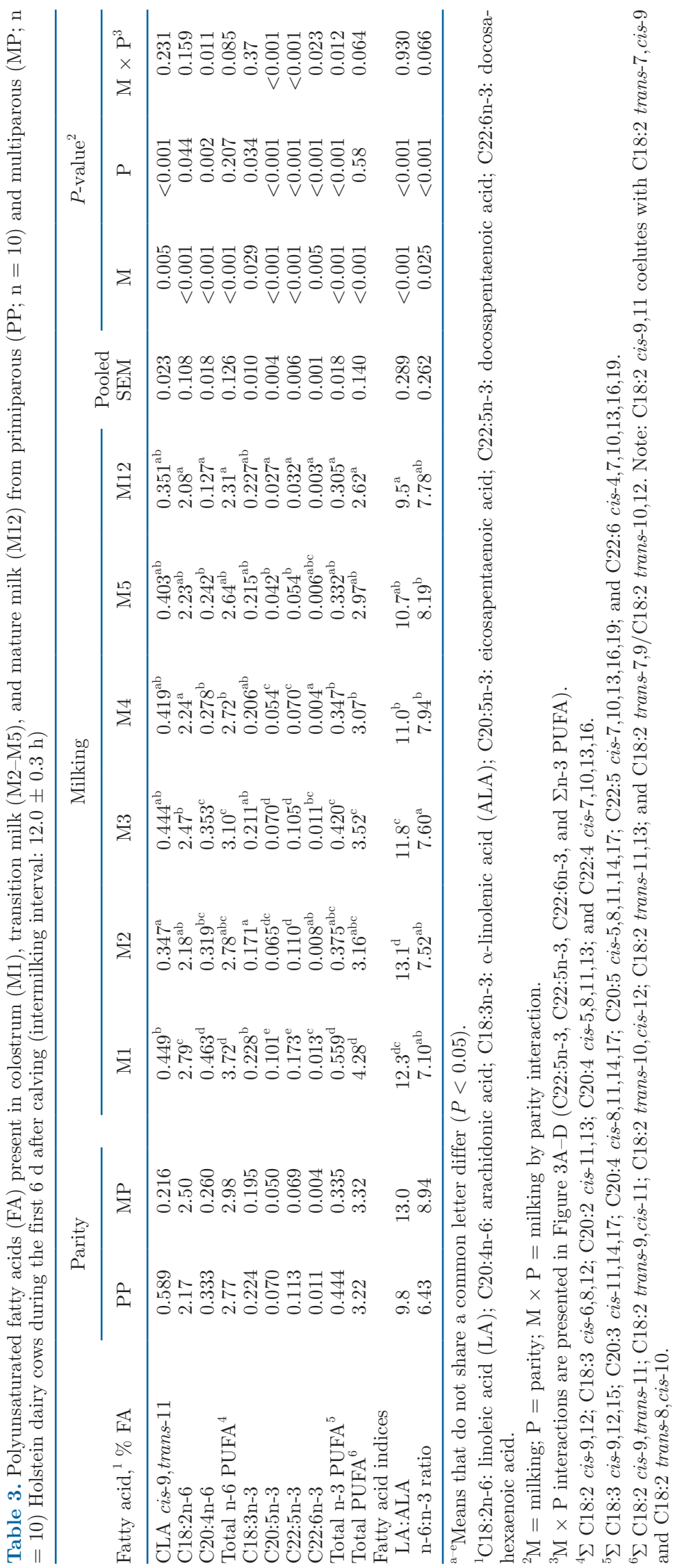


$\mathbf{A}$
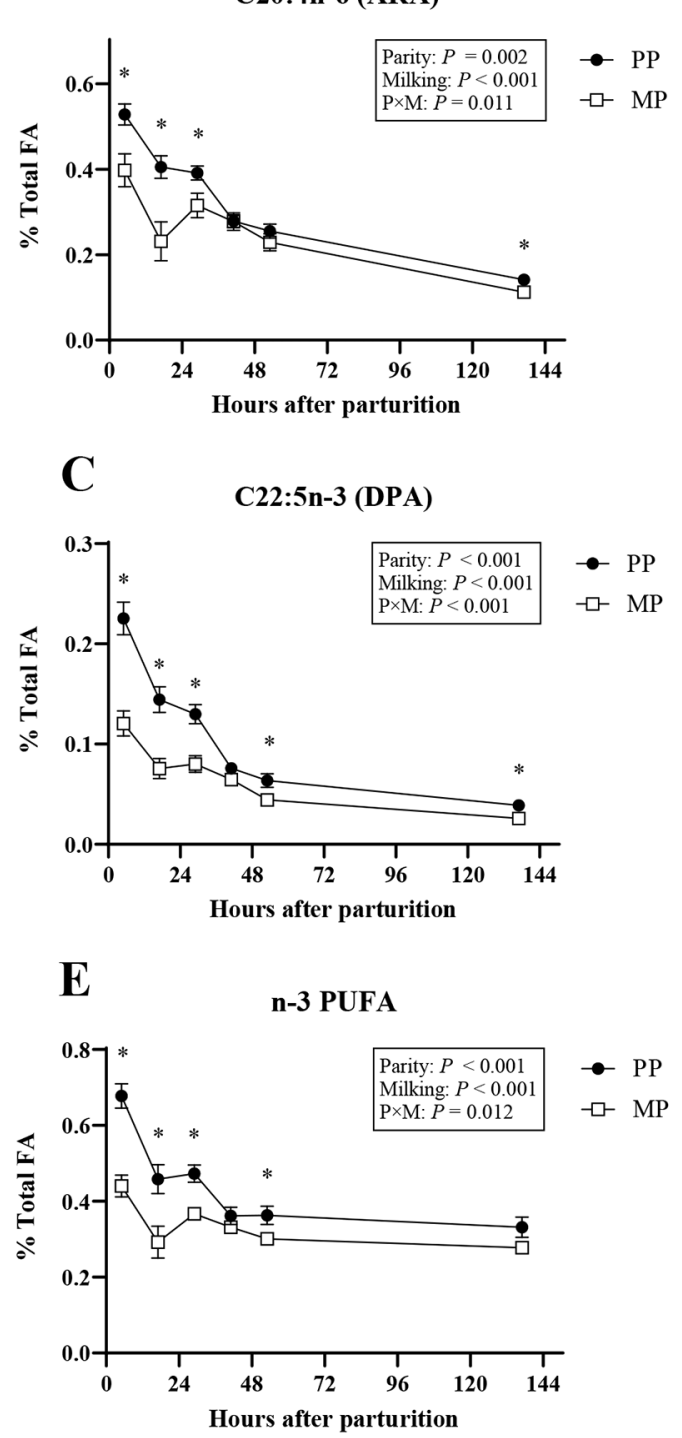

B

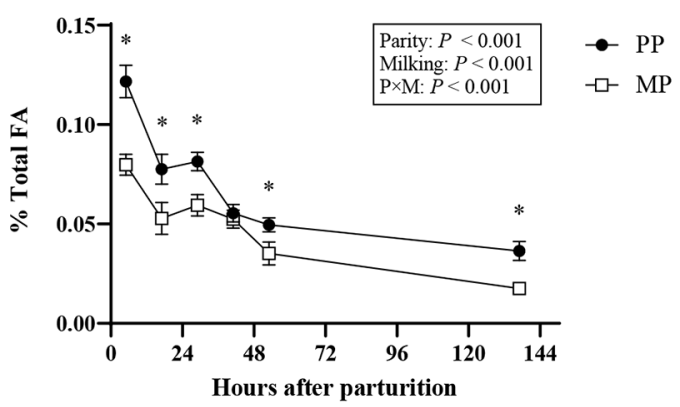

D

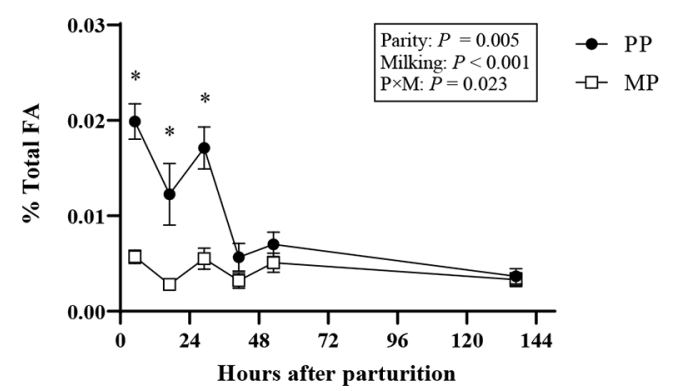

Figure 3. Polyunsaturated fatty acids (FA), including arachidonic acid (ARA; A), eicosapentaenoic acid (EPA; B), docosapentaenoic acid $(\mathrm{DPA} ; \mathrm{C})$, docosahexaenoic acid (DHA; D), and n-3 PUFA (E), from colostrum, transition, and mature milks of primiparous $(\mathrm{PP} ; \mathrm{n}=10)$ and multiparous Holstein dairy cows (MP; $\mathrm{n}=10)$ during the first week of lactation. Data are presented as LSM and SEM. Significant interactions between milking $(\mathrm{M})$ and parity $(\mathrm{P})$ at each time point are indicated by $*(P \leq 0.05)$.

S3B). Higher yields of C8:0 were also present for PP cows at M1 and M2 and for MP cows at M12 $(P=$ 0.005; Supplemental Figure S3C). The production of C16:0, C20:0, and C22:0, as well as total SFA, was not affected $(P \geq 0.055)$ by milking. However, parity by milking interactions were present. Yields of C16:0 were higher in the colostrum of PP cows and in M4 and M12 of MP cows $(P \leq 0.002$; Supplemental Figure S3D). Interactions of parity by milking also translated to higher $\mathrm{C} 20: 0$ and $\mathrm{C} 22: 0$ for PP cows in colostrum $(P \leq 0.014$; Supplemental Figure S3E and F). Total SFA yield was greater in MP cows at M12 $(P=0.002$; Supplemental
Figure S3G). Yield of BCFA was higher $(P=0.009)$ in milk from PP cows, and, although BCFA yield was greater $(P=0.002)$ at $\mathrm{M} 5$ and M12 relative to M2 and M3, it was similar between colostrum and subsequent milkings. With the exceptions of cis-C18:1 and cis-MUFA, yields of all MUFA were greater $(P \leq 0.003)$ for PP as opposed to MP cows. A parity by milking interaction was present for trans-C16:1 and translated to higher yields for PP than MP cows throughout all milkings $(P<0.001)$. Although trans-C16:1 was higher in the colostrum of PP cows relative to mature milk, trans-C16:1 yields in MP cows remained relatively 
stable $(P=0.028$; Supplemental Figure S3H). Monounsaturated FA yields did not differ $(P \geq 0.050)$ between colostrum, transition milk, and mature milk. Yields of EPA, ARA, DPA, and DHA differed $(P \leq 0.021)$ with respect to milking. Typically, these yields were greater in colostrum and transition milking than in mature milk. However, the total yields of n-3 and n-6 PUFA were not affected $(P \geq 0.76)$ by milking. Primiparous cows produced milk with greater $(P \leq 0.006)$ yields of EPA, ARA, DPA, and DHA than MP cows. Apart from cis-9,trans-11 CLA, a milking-parity interaction was present for all PUFA classes and groups $(P \leq 0.003)$. Yields of LA were greater in colostrum of $\mathrm{PP}$ cows followed by higher yields for MP cows at M4 and M12 $(P=0.001 ;$ Supplemental Figure S3I). Yield of ARA $(P=0.003$; Supplemental Figure S3J $)$ was greater at M2 for PP cows, and yield of n-6 PUFA $(P=0.001$; Supplemental Figure S3K) was greater at M4 in MP cows. Greater yields of EPA (M1 and M3; $P=0.012$; Supplemental Figure S3L), DHA (M1-M3; $P=0.012$; Supplemental Figure S3M), DPA (M1-M3; $P=0.002$; Supplemental Figure S3N), and n-3 PUFA (M1-M2; $P<0.001$; Supplemental Figure S3O) were present in milk of PP cows.

\section{Principal Component Analysis}

Results from the PCA are shown in Figure 4, displaying the evolution of the FA profile from colostrum through to the subsequent milkings. A clear transition is visible between colostrum and mature milk. The colostrum FA profile appeared to be fully distinct from M5 and M12. In addition, the M2 FA profile appeared to be distinct from that of M12. Additionally, the PCA showed that parity did not cause distinct groups.

\section{DISCUSSION}

Bovine colostrum supports the health and welfare of young calves by providing essential bioactive compounds and immune factors (Blum and Hammon, 2000; Godden, 2008). Developing knowledge regarding changes in FA profile from colostrum and transition milk to whole milk is important to understand the physiology of the dairy cow and the requirements of neonatal calves. As such, our study aimed to evaluate the colostrum FA profile in comparison with either transition milk or mature milk. Broadly, we found a lower proportion of SCFA in colostrum, whereas proportions of palmitic acid, myristic acid, and n- 3 and n- 6 PUFA were elevated in colostrum and transition milk. Despite milk yield being greater at M12 compared with colostrum (Fischer-Tlustos et al., 2020), the yields of n-3 and n-6 PUFA were still greater in colostrum than mature milk of PP cows but not MP cows. Indeed, parity substantially influenced the FA profile of colostrum and subsequent milkings, which has previously been described (Bilal et al., 2014; Contarini et al., 2014; O'Callaghan et al., 2020). This may be related to differences in energy requirements and partitioning, as well as differences in FA synthesis between PP and MP cows (Miller et al., 2006).

Supplementing n-3 and n-6 PUFA in milk replacers or whole milk improves health and growth performance of calves (Karcher et al., 2014; Garcia et al., 2015; McDonnell et al., 2019). Additionally, supplementation of n-3 PUFA in colostrum mitigated inflammation in calves in the week after birth and may confer longterm health benefits (Opgenorth et al., 2020a,b). In the current study, elevated proportions of PUFA from the $\mathrm{n}-3(+45 \%)$ and n- $6(+38 \%)$ series were observed in colostrum compared with mature milk. This is consistent with results from Contarini et al. (2014), where higher proportions of $\mathrm{n}-3(+48 \%)$ and $\mathrm{n}-6$ PUFA $(+17 \%)$ were observed in colostrum ( $24 \mathrm{~h}$ after calving) than in mature milk (120 h after calving). Polyunsaturated FA in milk are mainly derived from desaturation and elongation of LA and ALA, which are dietary precursors, although LA and ALA can also originate from adipose tissue mobilization, leading to increases in plasma NEFA concentrations in early lactation (Sardesai, 1992; Bell, 1995; Gross et al., 2011).

Long-chain PUFA are important for numerous cellular processes. Essential FA and specialized pro-resolving mediators formed in the cells by the metabolism of PUFA are critical for growth, organogenesis, regulation of inflammation, and neurodevelopment (Cheruku et al., 2002; Helland et al., 2003; Ramiro-Cortijo et al., 2020). Linoleic acid is primarily elongated to ARA and dihomogamma LA (Noble et al., 1978), whereas ALA primarily precedes EPA and DHA (Sardesai, 1992). In the current study, LA was substantially elevated $(+25 \%)$ in colostrum and transition milk than in mature milk, supporting previous findings (Leiber et al., 2011; O'Callaghan et al., 2020). In contrast, ALA concentrations remained relatively stable throughout the different milkings, indicating that neonatal calves may be provided with a larger pool of precursors through colostrum for ARA rather than EPA and DHA synthesis. These long-chain PUFA are then used to synthesize inflammatory molecules called eicosanoids, including prostaglandins, leukotrienes, and resolvins (Schmitz and Ecker, 2008). Interestingly, ARA is the precursor of proinflammatory eicosanoids, whereas EPA and DHA lead to anti-inflammatory eicosanoids (Noble et al., 1978; Sardesai, 1992; Calder, 2010). This means that colostrum could potentially modulate an inflammatory response in the neonate. Inflammation is proposed to 
Wilms et al.: FATTY ACID PROFILES IN BOVINE MILK

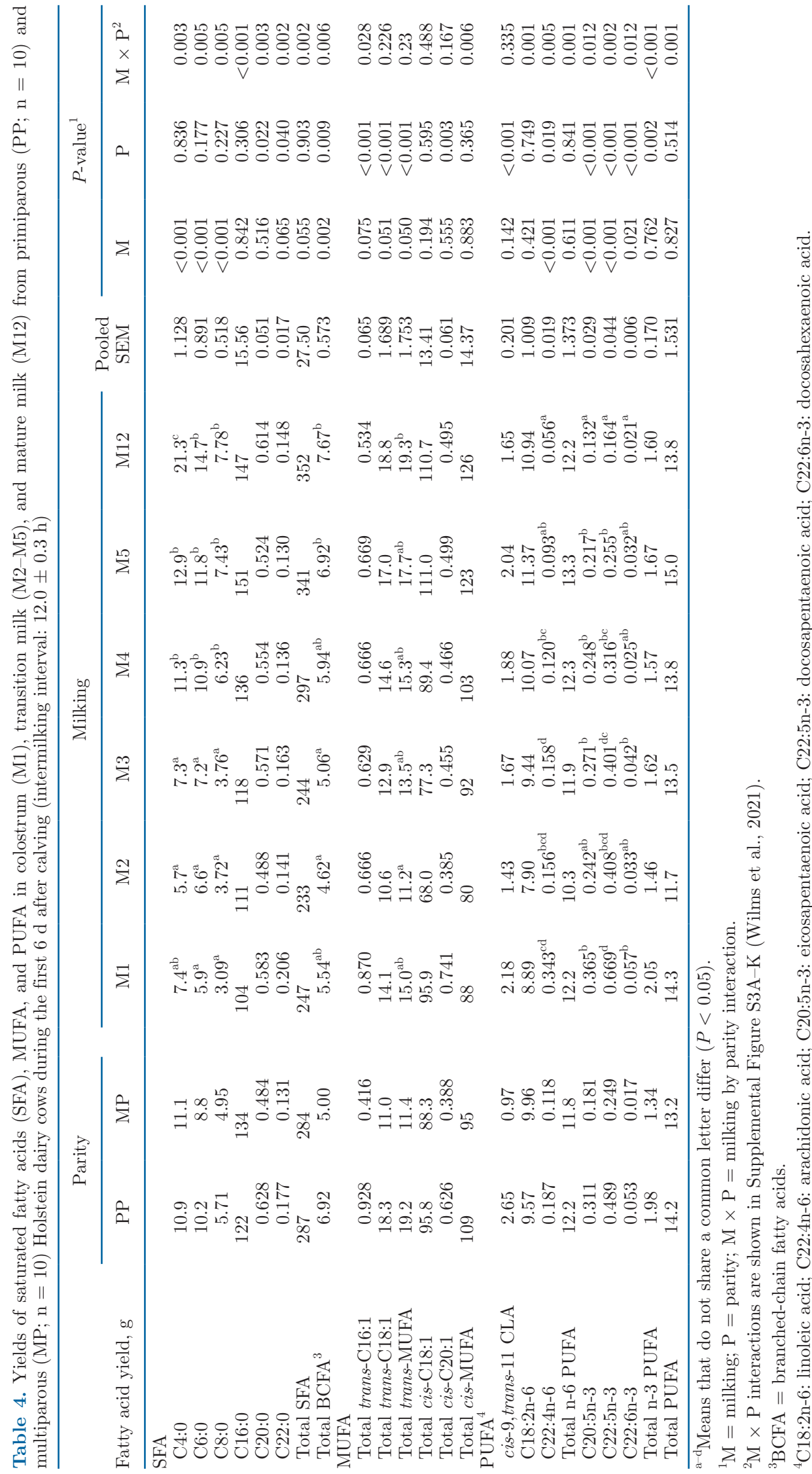


have a role in physiological adaptations (Norman, et al., 2007; Medzhitov, 2010; Bradford et al., 2015) and, speculatively, could aid neonates in the transition from the in utero to the ex utero environment. Although no effect of milking was detected on the n- $6: n-3$ ratio, the LA:ALA ratio was $23 \%$ higher in colostrum than mature milk. This higher ratio was the consequence of the higher LA concentration of colostrum.

Furthermore, results showed that ARA was $73 \%$ higher in colostrum than mature milk. Arachidonic acid is essential for infant growth, brain development, and health (Jasani et al., 2017); it serves as a precursor to eicosanoids, which are important for immunity and immune response (Hadley et al., 2016). Similarly, EPA was $73 \%$ higher in colostrum than mature milk and is used to produce eicosanoids, signaling molecules that play numerous roles, including reducing inflammation in the body and brain (Meydani, 1996; Endres et al., 1989). Interestingly, DHA, one of the most important n-3 PUFA, was elevated (+79\%) only in the colostrum of PP cows. The role of DHA in newborn development has been associated with cognitive and visual development, as well as immune functions (Smith and Rouse, 2017). Results also showed higher proportions of DPA in colostrum and transition milk, as well as relative to DHA and EPA. Although the role of DPA in early development is not fully known (Li et al., 2016), studies have shown that it may partly act as a storage form of DHA and EPA (Cao et al., 2006; Kaur et al., 2010). Similar to DHA, DPA also showed anti-inflammatory and pro-resolving functions (Groeger et al., 2010; Cipollina et al., 2014) and may therefore play a role in infant nervous system development (Cheruku et al., 2002; Helland et al., 2003). In neonates, the maximal capacity to elongate LA and ALA does not occur until several weeks postnatally; thus, higher proportions and yields of long-chain PUFA in colostrum and transition milk may have significant benefit to the neonatal calf (Sanders and Naismith, 1979). The greater proportions of n-3 and n- 6 long-chain PUFA in colostrum are consistent between PP and MP cows, which present different physiological requirements for these FA. This may indicate a preferential uptake by the mammary gland that complements the needs of the neonate.

De novo FA are synthesized in the mammary gland from acetate and butyrate and are often used as an indicator of ruminal function (Woolpert et al., 2017). Consistent with the work of O'Callaghan et al. (2020), the effect of milking was significant for de novo FA, including C4:0 to C15:0. However, no clear differences between colostrum, transition, and mature milk were detected. Although some FA (C4:0, C6:0, C8:0, C10:0) were lower in colostrum, the proportion of myristic acid (C14:0) was $27 \%$ higher in colostrum compared with

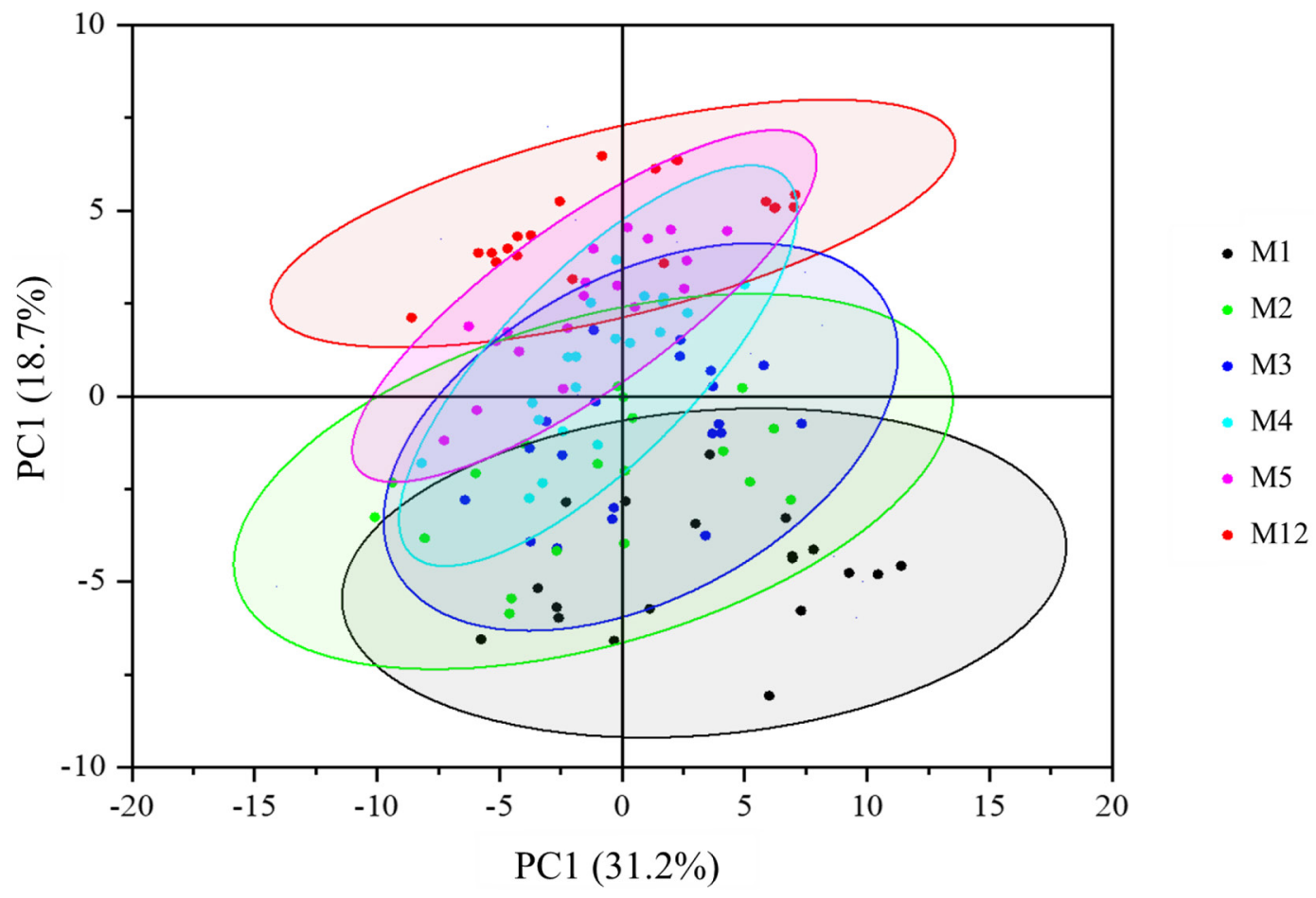

Figure 4. Principal component (PC) analysis displaying the changes occurring as milk transition from colostrum to mature milk over the 6 d following parturition (milkings: M1, black; M2, green; M3, dark blue; M4, light blue; M5, pink; M12, red). 
mature milk. Greater myristic acid proportions may allow for increased colostrum intake, as Gutiérrez-García et al. (2017) showed that myristic acid resulted in the highest appetitive response in neonates. The proportions of $\mathrm{C} 4: 0$ and $\mathrm{C} 6: 0$ were respectively $39 \%$ and $50 \%$ lower in colostrum than mature milk, as reported in previous studies (O'Callaghan et al., 2020). Lower proportions of $\mathrm{C} 4: 0$ and $\mathrm{C} 6: 0$ coupled with lower fat yield in colostrum than mature milk led to lower yields of C4:0 and C6:0 in colostrum. Beyond its role as primary nutrient, C4:0 (butyric acid) is also a cellular mediator and regulator of gut cell functions, including gene expression, gut tissue development, immune modulation, and oxidative stress reduction in neonates (Bedford and Gong, 2018). In artificial rearing systems, where calves are fed milk replacers that typically do not contain C4:0, improved growth of calves receiving sodium butyrate is attributed to improved insulin sensitivity and digestive functions by enhanced production of digestive enzymes and increased absorptive capacities in the upper small intestine (as reviewed by Guilloteau et al., 2009; Gorka et al., 2011; Kato et al., 2011). Butyric acid is important for stimulation of epithelial differentiation and may reduce paracellular permeability during the process of gut closure (Hiltz and Laarman, 2019). The lower proportions of butyrate in colostrum and transition milk may prolong the period of intestinal permeability, thereby promoting the permeation of immunoglobulins across the gut (Hiltz and Laarman, 2019).

Proportions of SFA remained stable throughout the different milkings and accounted for about $65 \%$ of total FA. Whereas SFA yield remained relatively stable for PP cows, MP cows had greater SFA yields in mature milk than colostrum, which is consistent with the higher milk yield in mature milk of MP than PP cows. Palmitic acid, a major SFA providing about $30 \%$ of total FA (or $10 \%$ of total energy intake), was $16 \%$ higher in colostrum compared with mature milk. This is consistent with previous studies investigating breast milk (Floris et al., 2020), goat milk (Marounek et al., 2012), and bovine milk (O'Callaghan et al., 2020). The lactation ration contained $1.3 \%$ palmitic acid, whereas the dry cow ration contained no added palmitic acid. As such, differences of palmitic acid proportions through time are a function of palmitic acid intakes. In bovine milk, 40 to $45 \%$ of palmitic acid is located at the sn- 2 position ( $\beta$-palmitate) on the glycerol backbone, and approximately $75 \%$ of palmitic acid is located at the sn-2 position in human breast milk (Bracco, 1994; Sun et al., 2018). The location of palmitic acid on the glycerol backbone is an important characteristic for digestion, as pancreatic lipase selectively hydrolyzes triglycerides at the sn- 1 and sn- 3 positions, resulting in free
FA and 2-monoglycerides (Lien, 1994). Following birth, neonates have a sterile intestinal lumen that is rapidly colonized by microorganisms (Biedermann and Rogler, 2013; Douglas-Escobar et al., 2013). Previous research underlined the role of $\beta$-palmitate configuration in intestinal mucosal homeostasis, gut microbiome, and immune response (Havlicekova et al., 2015; Jiang et al., 2018). In addition, research has shown that, although to a lesser extent than myristic acid, palmitic acid also increased appetitive responses in neonates, potentially allowing for greater colostrum uptake (Contreras et al., 2013; Gutiérrez-García et al., 2017). Another interesting aspect related to palmitic acid is its role as the main substrate for de novo ceramide synthesis, which can then be used to synthesize sphingomyelin (Rico et al., 2016; Dei Cas et al., 2020). Both ceramide and sphingomyelin are implicated in numerous cellular functions, as well as in brain and immune system development in newborn animals (Dei Cas et al., 2020). Such metabolic function, as well as the olfactive properties, could explain why a higher proportion of palmitic acid is found in human and bovine colostrum compared with mature milk.

Branched-chain FA are usually SFA with one or more methyl branches on the carbon chain (Ran-Ressler et al., 2008). The proportion of BCFA was $11 \%$ lower in colostrum and transition milk than mature milk. These results are consistent with those of Xin et al. (2020), who showed that BCFA were $35 \%$ lower in colostrum than transition milk and mature milk. Those authors attributed lower colostral BCFA percentages to the decline in postpartum DMI, which could lead to lower substrate availability for FA synthesis. Ran-Ressler et al. (2008) showed that BCFA is a major constituent of the gastrointestinal tract of newborn infants and speculated that BCFA may be involved in gut development. Supply of BCFA to neonates originates from the ingestion of amniotic fluid in utero and from later milk consumption (Nicolaides and Ray, 1965; Sherman et al., 1990; Ran-Ressler et al., 2014). In a mouse model, dietary BCFA supplementation was shown to reduce the incidence of necrotizing enterocolitis in pups, increase the abundance of BCFA-containing bacteria, and have an anti-inflammatory response (Ran-Ressler et al., 2011). Further research is needed to evaluate the potential relevance of BCFA for newborn calves.

Oleic acid (C18:1n-9) constituted the largest part of MUFA and represented approximately $20 \%$ of total FA in the current study. A trend for milking was observed, with oleic acid tending to be lower in colostrum than mature milk. Although cis-MUFA did not differ throughout milkings, trans-MUFA ( $\sim 3.5 \%$ of total FA) were $13 \%$ lower in colostrum than mature milk. These results are consistent with findings reported by Paszc- 
zyk et al. (2005) and Contarini et al. (2014), where total trans-FA increased over the course of lactation and the lowest proportion was observed in colostrum. The biological implications of lower colostral trans-MUFA in calves have not been studied. Overall, the proportions of trans-FA were $42 \%$ higher in PP cows. This parity difference is consistent with prior observations (Contarini et al., 2014). The elevated proportion of trans-MUFA was mostly driven $(\sim 95 \%)$ by trans-C18:1 FA, with C18:1 trans-11 (vaccenic acid) being present in the highest amount ( $1.5 \%$ of total FA). Vaccenic acid is a precursor of cis-9,trans-11 CLA (rumenic acid, RA), which is mainly synthesized endogenously in the mammary gland through the action of the mammary $\Delta-9$ desaturase (Griinari et al., 2000; Bauman and Lock, 2009). Despite the relationship between vaccenic acid and RA, no clear differences between colostrum and mature milk were detected for RA. These results are inconsistent with the report of O'Callaghan et al. (2020), who found lower proportions of RA in colostrum samples. Concentration of CLA in milk fat is directly affected by the substrate supply and the extent of biohydrogenation in the rumen (Kelly et al., 1998; Dhiman et al., 1999). One-and-a-half to 5-fold higher CLA concentrations were reported in milk fat of pasture-fed dairy cows compared with cows fed TMR or concentrates (Stockdale et al., 2003; Rouillé and Montourcy, 2010; Hurtaud et al., 2014). In the study from O'Callaghan et al. (2020), cows were fed TMR before calving and were then turned to grass following calving, which may explain the lower colostral RA proportions.

The current study showed that parity largely influences the FA profile and yield of colostrum and subsequent milkings. These findings align with those of Contarini et al. (2014), who found that parity substantially affected the proportion of most FA, as well as cholesterol and triglyceride composition. Those authors attributed their observations to differences in energy requirements (Contarini et al., 2014). Primiparous cows have an additional nutrient requirement to support growth and, thus, altered nutrient partitioning relative to MP cows. Additionally, it is well known that PP cows have lower DMI and that differences in prepartum metabolizable energy intake can alter the colostral FA profile (Mann et al., 2016). Unfortunately, DMI was not recorded in the present study. Previous research also showed that PP cows had a reduced FA synthesized expression in the mammary gland compared with MP cows (Miller et al., 2006). In the current study, the same pre- and postpartum diets were fed to PP and MP cows. However, we cannot exclude the possibility that the diet fed before the close-up phase did not have long-term effects on the FA profile of milk fat when cows mobilized their own fat stores. Despite differences in FA profiles between PP and MP cows, the FA pattern throughout milkings was similar. For instance, this was the case with SCFA, most long-chain PUFA, and trans-FA. This could mean a potential biological relevance for calf health and development.

Knowledge generated regarding milk fat composition from colostrum to mature milk shows the value of feeding transition milk to calves. This knowledge can also benefit colostrum and milk replacers, and ultimately early-life nutritional management, to better meet the requirements of neonatal calves. Milk replacers for calves usually include low levels of fat $(<20 \%$ DM; Amado et al., 2019; Echeverry-Munera et al., 2021) and use alternative fat sources (e.g., palm, coconut, lard) with an overall FA profile that largely differs from bovine milk fat (Hill et al., 2007). Consequently, SCFA and long-chain PUFA are usually deficient or absent from milk replacers for calves. Literature shows that despite C4:0 and C6:0 being critical for gut development and immune functions in neonates, concentrations in the first days after birth should be moderate. In contrast, PUFA content should be elevated in the first days after birth, when calves have not yet reached their full capacity to elongate LA and ALA. Although the n-6: n-3 ratio did not differ, the LA:ALA ratio was higher in colostrum than mature milk, which may also play a substantial metabolic role. Additionally, the PCA showed that colostrum and M2 were distinct from M12. These findings support the idea that neonatal calves may benefit from a gradual transition from colostrum to mature milk (van Niekerk et al., 2021), a practice that is not common in operations that feed either whole milk or milk replacer immediately after the initial colostrum meals. Future research should also investigate the FA composition of colostrum of grazing dairy cows, which typically have higher proportions of n-3 and n- 6 PUFA than cows that are artificially fed. Benoit et al. (2014) showed that a dairy cream from pasture-raised cows led to improved metabolic outcomes and gut barrier function compared with a standard dairy cream in rats. The FA profile presented in the current paper may therefore not represent that of grazing cattle (Moate et al., 2007).

\section{CONCLUSIONS}

This study showed that colostrum, transition milk, and mature milk have distinct FA profiles. Higher proportions of n-3 and n-6 PUFA, as well as palmitic and myristic acids, were observed in colostrum and transition milk. In contrast, proportions of SCFA (C4:0 and C6:0), BCFA, and trans-MUFA were lower in colostrum than mature milk. These specificities of colostrum may highlight specific requirements of newborn calves. For 
instance, the maximal capacity to elongate and desaturate linoleic and linolenic acids occurs several weeks postnatally and could partly explain the higher PUFA in colostrum. Lower SCFA, especially butyrate, could allow for improved permeation of immunoglobulins across the gut. Higher palmitic acid, and more specifically higher $\beta$-palmitate, may play a role in establishing the gut microbiome as well as mucosal homeostasis. Increased proportions of certain SFA, such as myristic acid, and to a lesser extent palmitic acid, result in increased appetitive responses in neonates, potentially to enhance colostrum consumption. The FA profile differed between primi- and multiparous cows and may reflect different nutrient requirements and altered nutrient partitioning.

\section{ACKNOWLEDGMENTS}

The authors are grateful for the funding support provided by Alberta Livestock and Meat Agency Ltd. (Edmonton, AB, Canada), the Saskatoon Colostrum Co. Ltd. (Saskatoon, SK, Canada), Alberta Milk (Edmonton, AB, Canada), SaskMilk (Regina, SK, Canada), the BC Dairy Association (Burnaby, BC, Canada), Dairy Farmers of Manitoba (Winnipeg, MB, Canada), Trouw Nutrition (Guelph, ON, Canada), Bayer Animal Health (Mississauga, ON, Canada), and the Natural Sciences and Engineering Research Council of Canada (Ottawa, ON). The authors also thank the staff at Breevliet Ltd. (Millet, AB, Canada) for their assistance with the collection of samples. The authors have not stated any conflicts of interest.

\section{REFERENCES}

Amado, L., H. Berends, L. N. Leal, J. Wilms, H. Van Laar, W. J. J. Gerrits, and J. Martín-Tereso. 2019. Effect of energy source in calf milk replacer on performance, digestibility, and gut permeability in rearing calves. J. Dairy Sci. 102:3994-4001. https://doi.org/10 $.3168 /$ jds.2018-15847.

Bauman, D. E., and A. L. Lock. 2009. Conjugated linoleic acid: Biosynthesis and nutritional significance. Pages 93-136 in Advanced Dairy Chemistry, Volume 2: Lipids. Springer US. https://doi.org/ 10.1007/0-387-28813-9_3.

Bedford, A., and J. Gong. 2018. Implications of butyrate and its derivatives for gut health and animal production. Anim. Nutr. 4:151159. https://doi.org/10.1016/J.ANINU.2017.08.010 (Zhongguo xu mu shou yi xue hui).

Bell, A. W. 1995. Regulation of organic nutrient metabolism during transition from late pregnancy to early lactation. J. Anim. Sci. 73:2804-2819. https://doi.org/10.2527/1995.7392804x.

Benoit, B., P. Plaisancié, A. Géloën, M. Estienne, C. Debard, E. Meugnier, E. Loizon, P. Daira, J. Bodennec, O. Cousin, H. Vidal, F. Laugerette, and M. C. Michalski. 2014. Pasture $v$. standard dairy cream in high-fat diet-fed mice: Improved metabolic outcomes and stronger intestinal barrier. Br. J. Nutr. 112:520-535. https://doi .org/10.1017/S0007114514001172.

Biedermann, L., and G. Rogler. 2013. Environmental factors and their impact on the intestinal microbiota: A role for human disease? Dig. Dis. 30(Suppl. 3):20-27. https://doi.org/10.1159/000342590.
Bilal, G., R. I. Cue, A. F. Mustafa, and J. F. Hayes. 2014. Effects of parity, age at calving and stage of lactation on fatty acid composition of milk in Canadian Holsteins. Can. J. Anim. Sci. 94:401-410. https://doi.org/10.4141/cjas2013-172.

Blum, J. W., and H. Hammon. 2000. Colostrum effects on the gastrointestinal tract, and on nutritional, endocrine and metabolic parameters in neonatal calves. Livest. Prod. Sci. 66:151-159. https: //doi.org/10.1016/S0301-6226(00)00222-0.

Bracco, U. 1994. Effect of triglyceride structure on fat absorption. Am. J. Clin. Nutr. 60:1002S-1009S. https://doi.org/10.1093/ajcn/60.6 $.1002 \mathrm{~S}$.

Bradford, B. J., K. Yuan, J. K. Farney, L. K. Mamedova, and A. J. Carpenter. 2015. Invited Review: Inflammation during the transition to lactation: New adventures with an old flame. J. Dairy Sci. 98:6631-6650. https://doi.org/10.3168/jds.2015-9683.

Calder, P. C. 2010. Omega-3 fatty acids and inflammatory processes. Nutrients 2:355-374. https://doi.org/10.3390/nu2030355.

Cao, J., K. A. Schwichtenberg, N. Q. Hanson, and M. Y. Tsai. 2006. Incorporation and clearance of omega-3 fatty acids in erythrocyte membranes and plasma phospholipids. Clin. Chem. 52:2265-2272. https://doi.org/10.1373/clinchem.2006.072322.

Cheruku, S. R., H. E. Montgomery-Downs, S. L. Farkas, E. B. Thoman, and C. J. Lammi-Keefe. 2002. Higher maternal plasma docosahexaenoic acid during pregnancy is associated with more mature neonatal sleep-state patterning. Am. J. Clin. Nutr. 76:608-613. https://doi.org/10.1093/ajcn/76.3.608.

Cipollina, C., S. R. Salvatore, M. F. Muldoon, B. A. Freeman, and F. J. Schopfer. 2014. Generation and dietary modulation of antiinflammatory electrophilic omega-3 fatty acid derivatives. PLoS One 9:e94836. https://doi.org/10.1371/journal.pone.0094836.

Contarini, G., M. Povolo, V. Pelizzola, L. Monti, A. Bruni, L. Passolungo, F. Abeni, and L. Degano. 2014. Bovine colostrum: Changes in lipid constituents in the first 5 days after parturition. J. Dairy Sci. 97:5065-5072. https://doi.org/10.3168/jds.2013-7517.

Contreras, C. M., A. G. Gutiérrez-García, R. Mendoza-López, J. F. Rodríguez-Landa, B. Bernal-Morales, and C. Díaz-Marte. 2013. Amniotic fluid elicits appetitive responses in human newborns: Fatty acids and appetitive responses. Dev. Psychobiol. 55:221-231. https://doi.org/10.1002/dev.21012.

Cruz-Hernandez, C., Z. Y. Deng, J. Q. Zhou, A. R. Hill, M. P. Yurawecz, P. Delmonte, M. M. Mossoba, M. E. R. Dugan, and J. K. G. Kramer. 2004. Methods for analysis of conjugated linoleic acids and trans-18:1 isomers in dairy fats by using a combination of gas chromatography, silver-ion thin-layer chromatography/gas chromatography, and silver-ion liquid chromatography. J. AOAC Int. 87:545-562. https://doi.org/10.1093/jaoac/87.2.545.

Daniel, J. B., N. C. Friggens, H. van Laar, K. L. Ingvartsen, and D. Sauvant. 2018. Modeling homeorhetic trajectories of milk component yields, body composition and dry-matter intake in dairy cows: Influence of parity, milk production potential and breed. Animal 12:1182-1195. https://doi.org/10.1017/S1751731117002828.

Dei Cas, M., R. Paroni, P. Signorelli, A. Mirarchi, L. Cerquiglini, S. Troiani, S. Cataldi, M. Codini, T. Beccari, R. Ghidoni, and E. Albi. 2020. Human breast milk as source of sphingolipids for newborns: Comparison with infant formulas and commercial cow's milk. J. Transl. Med. 18:481. https://doi.org/10.1186/s12967-020 $-02641-0$.

Dhiman, T. R., G. R. Anand, L. D. Satter, and M. W. Pariza. 1999. Conjugated linoleic acid content of milk from cows fed different diets. J. Dairy Sci. 82:2146-2156. https://doi.org/10.3168/jds.S0022 -0302(99)75458-5.

Delplanque, B., R. Gibson, B. Koletzko, A. Lapillonne, and B. Strandvik. 2015. Lipid quality in infant nutrition: current knowledge and future opportunities. J. Pediatr. Gastroenterol. Nutr. 61:8-17. https://doi.org/10.1097/MPG.0000000000000818.

Douglas-Escobar, M., E. Elliott, and J. Neu. 2013. Effect of intestinal microbial ecology on the developing brain. JAMA Pediatr. 167:374-379. https://doi.org/10.1001/jamapediatrics.2013.497.

Dugan, M. E. R., J. K. G. Kramer, W. M. Robertson, W. J. Meadus, N. Aldai, and D. C. Rolland. 2007. Comparing subcutaneous adipose tissue in beef and muskox with emphasis on trans 18:1 and 
conjugated linoleic acids. Lipids 42:509-518. https://doi.org/10 .1007/S11745-007-3051-7.

Echeverry-Munera, J., L. N. Leal, J. N. Wilms, H. Berends, J. H. C. Costa, M. Steele, and J. Martín-Tereso. 2021. Effect of partial exchange of lactose with fat in milk replacer on ad libitum feed intake and performance in dairy calves. J. Dairy Sci. 104:5432-5444. https://doi.org/10.3168/jds.2020-19485.

Endres, S., R. Ghorbani, V. E. Kelley, K. Georgilis, G. Lonnemann, J. W. M. van der Meer, J. G. Cannon, T. S. Rogers, M. S. Klempner, P. C. Weber, E. J. Schaefer, S. M. Wolff, and C. A. Dinarello. 1989. The effect of dietary supplementation with n-3 polyunsaturated fatty acids on the synthesis of interleukin-1 and tumor necrosis factor by mononuclear cells. N. Engl. J. Med. 320:265-271. https://doi.org/10.1056/NEJM198902023200501.

Fahey, M. J., A. J. Fischer, M. A. Steele, and S. L. Greenwood. 2020. Characterization of the colostrum and transition milk proteomes from primiparous and multiparous Holstein dairy cows. J. Dairy Sci. 103:1993-2005. https://doi.org/10.3168/jds.2019-17094.

Feng, S., A. L. Lock, and P. C. Garnsworthy. 2004. Technical note: A rapid lipid separation method for determining fatty acid composition of milk. J. Dairy Sci. 87:3785-3788. https://doi.org/10.3168/ JDS.S0022-0302(04)73517-1.

Fischer-Tlustos, A. J., K. Hertogs, J. K. van Niekerk, M. Nagorske, D. M. Haines, and M. A. Steele. 2020. Oligosaccharide concentrations in colostrum, transition milk, and mature milk of primi- and multiparous Holstein cows during the first week of lactation. J. Dairy Sci. 103:3683-3695. https://doi.org/10.3168/jds.2019-17357.

Floris, L. M., B. Stahl, M. Abrahamse-Berkeveld, and I. C. Teller. 2020. Human milk fatty acid profile across lactational stages after term and preterm delivery: A pooled data analysis. Prostaglandins Leukot. Essent. Fatty Acids 156:102023. https://doi.org/10.1016/ j.plefa.2019.102023.

Garcia, M., J. H. Shin, A. Schlaefli, L. F. Greco, F. P. Maunsell, J. E. P. Santos, C. R. Staples, and W. W. Thatcher. 2015. Increasing intake of essential fatty acids from milk replacer benefits performance, immune responses, and health of preweaned Holstein calves. J. Dairy Sci. 98:458-477. https://doi.org/10.3168/jds.2014 -8384 .

Godden, S. 2008. Colostrum management for dairy calves. Vet. Clin. North Am. Food Anim. Pract. 24:19-39. https://doi.org/10.1016/ j.cvfa.2007.10.005.

Górka, P., Z. M. Kowalski, P. Pietrzak, A. Kotunia, W. Jagusiak, J. J. Holst, P. Guilloteau, and R. Zabielski. 2011. Effect of method of delivery of sodium butyrate on rumen development in newborn calves. J. Dairy Sci. 94:5578-5588. https://doi.org/10.3168/JDS .2011-4166.

Griinari, J. M., B. A. Corl, S. H. Lacy, P. Y. Chouinard, K. V. V. Nurmela, and D. E. Bauman. 2000. Conjugated linoleic acid is synthesized endogenously in lactating dairy cows by $\Delta 9$-desaturase. J. Nutr. 130:2285-2291. https://doi.org/10.1093/jn/130.9.2285.

Groeger, A. L., C. Cipollina, M. P. Cole, S. R. Woodcock, G. Bonacci, T. K. Rudolph, V. Rudolph, B. A. Freeman, and F. J. Schopfer. 2010. Cyclooxygenase-2 generates anti-inflammatory mediators from omega-3 fatty acids. Nat. Chem. Biol. 6:433-441. https://doi .org/10.1038/nchembio.367.

Gross, J., H. A. van Dorland, R. M. Bruckmaier, and F. J. Schwarz. 2011. Milk fatty acid profile related to energy balance in dairy cows. J. Dairy Res. 78:479-488. https://doi.org/10.1017/ S0022029911000550.

Grote, V., E. Verduci, S. Scaglioni, F. Vecchi, G. Contarini, M. Giovannini, B. Koletzko, and C. Agostoni. 2016. Breast milk composition and infant nutrient intakes during the first 12 months of life. Eur. J. Clin. Nutr. 70:250-256. https://doi.org/10.1038/ejcn.2015.162.

Guilloteau, P., R. Zabielski, J. C. David, J. W. Blum, J. A. Morisset, M. Biernat, J. Woliński, D. Laubitz, and Y. Hamon. 2009. Sodiumbutyrate as a growth promoter in milk replacer formula for young calves. J. Dairy Sci. 92:1038-1049. https://doi.org/10.3168/JDS 2008-1213.

Gutiérrez-García, A. G., C. M. Contreras, and C. Díaz-Marte. 2017. Myristic acid in amniotic fluid produces appetitive responses in human newborns. Early Hum. Dev. 115:32-37. https://doi.org/10 .1016/j.earlhumdev.2017.08.009.

Hadley, K. B., A. S. Ryan, S. Forsyth, S. Gautier, and N. Salem. 2016. The essentiality of arachidonic acid in infant development. Nutrients 8:216. https://doi.org/10.3390/nu8040216.

Havlicekova, Z., M. Jesenak, P. Banovcin, and M. Kuchta. 2015. Betapalmitate - A natural component of human milk in supplemental milk formulas. Nutr. J. 15:28. https://doi.org/10.1186/s12937-016 $-0145-1$.

Helland, I. B., L. Smith, K. Saarem, O. D. Saugstad, and C. A. Drevon. 2003. Maternal supplementation with very-long-chain n-3 fatty acids during pregnancy and lactation augments children's IQ at 4 years of age. Pediatrics 111:e39-e44. https://doi.org/10.1542/ peds.111.1.e39.

Hill, T. M., J. M. Aldrich, R. L. Schlotterbeck, and H. G. Bateman II.. 2007. Effects of changing the fat and fatty acid composition of milk replacers fed to neonatal calves. Prof. Anim. Sci. 23:135-143. https://doi.org/10.15232/S1080-7446(15)30953-0.

Hiltz, R. L., and A. H. Laarman. 2019. Effect of butyrate on passive transfer of immunity in dairy calves. J. Dairy Sci. 102:4190-4197. https://doi.org/10.3168/jds.2018-15555.

Honan, M. C., M. J. Fahey, A. J. Fischer-Tlustos, M. A. Steele, and S. L. Greenwood. 2020. Shifts in the Holstein dairy cow milk fat globule membrane proteome that occur during the first week of lactation are affected by parity. J. Anim. Sci. Biotechnol. 11:81. https://doi.org/10.1186/s40104-020-00478-7.

Hurtaud, C., M. Dutreuil, M. Coppa, C. Agabriel, and B. Martin. 2014. Characterization of milk from feeding systems based on herbage or corn silage with or without flaxseed and authentication through fatty acid profile. Dairy Sci. Technol. 94:103-123. https:/ /doi.org/10.1007/s13594-013-0147-0.

Jasani, B., K. Simmer, S. K. Patole, and S. C. Rao. 2017. Long chain polyunsaturated fatty acid supplementation in infants born at term. Cochrane Database Syst. Rev. CD000376. https://doi.org/ 10.1002/14651858.CD000376.PUB4.

Jensen, R. G., A. M. Ferris, and C. J. Lammi-Keefe. 1991. The composition of milk fat. J. Dairy Sci. 74:3228-3243. https://doi.org/10 .3168/jds.S0022-0302(91)78509-3.

Jiang, T., B. Liu, J. Li, X. Dong, M. Lin, M. Zhang, J. Zhao, Y. Dai, and L. Chen. 2018. Association between sn-2 fatty acid profiles of breast milk and development of the infant intestinal microbiome. Food Funct. 9:1028-1037. https://doi.org/10.1039/C7FO00088J.

Karcher, E. L., T. M. Hill, H. G. Bateman II, R. L. Schlotterbeck, N. Vito, L. M. Sordillo, and M. J. VandeHaar. 2014. Comparison of supplementation of n-3 fatty acids from fish and flax oil on cytokine gene expression and growth of milk-fed Holstein calves. J. Dairy Sci. 97:2329-2337. https://doi.org/10.3168/jds.2013-7160.

Kato, S. I., K. Sato, H. Chida, S. G. Roh, S. Ohwada, S. Sato, P. Guilloteau, and K. Katoh. 2011. Effects of Na-butyrate supplementation in milk formula on plasma concentrations of GH and insulin, and on rumen papilla development in calves. J. Endocrinol. 211:241-248. https://doi.org/10.1530/JOE-11-0299.

Kaur, G., D. P. Begg, D. Barr, M. Garg, D. Cameron-Smith, and A. J. Sinclair. 2010. Short-term docosapentaenoic acid (22:5 n-3) supplementation increases tissue docosapentaenoic acid, DHA and EPA concentrations in rats. Br. J. Nutr. 103:32-37. https://doi .org/10.1017/S0007114509991334.

Kelly, M. L., E. S. Kolver, D. E. Bauman, M. E. Van Amburgh, and L. D. Muller. 1998. Effect of intake of pasture on concentrations of conjugated linoleic acid in milk of lactating cows. J. Dairy Sci. 81:1630-1636. https://doi.org/10.3168/jds.S0022-0302(98)75730 -3 .

Kramer, J. K. G., M. Hernandez, C. Cruz-Hernandez, J. Kraft, and M. E. R. Dugan. 2008. Combining results of two GC separations partly achieves determination of all cis and trans 16:1, 18:1, 18:2 and 18:3 except CLA isomers of milk fat as demonstrated using ag-ion SPE fractionation. Lipids 43:259-273. https://doi.org/10 $.1007 / \mathrm{s} 11745-007-3143-4$.

Laliotis, G. P., I. Bizelis, and E. Rogdakis. 2010. Comparative approach of the de novo fatty acid synthesis (lipogenesis) between ruminant and non ruminant mammalian species: From biochemi- 
cal level to the main regulatory lipogenic genes. Curr. Genomics 11:168-183. https://doi.org/10.2174/138920210791110960.

Lammi-Keefe, C. J., and R. G. Jensen. 1984. State of the art: Lipids in human milk: A review. 2: Composition and fat-soluble vitamins. J. Pediatr. Gastroenterol. Nutr. 3:172-198. https://doi.org/10.1097/ 00005176-198403000-00004.

Leiber, F., R. Hochstrasser, H.-R. Wettstein, and M. Kreuzer. 2011. Feeding transition cows with oilseeds: Effects on fatty acid composition of adipose tissue, colostrum and milk. Livest. Sci. 138:1-12. https://doi.org/10.1016/j.livsci.2010.11.016.

Li, J., H. Yin, D. M. Bibus, and O. A. Byelashov. 2016. The role of omega-3 docosapentaenoic acid in pregnancy and early development. Eur. J. Lipid Sci. Technol. 118:1692-1701. https://doi.org/ 10.1002/ejlt.201600076.

Lien, E. L. 1994. The role of fatty acid composition and positional distribution in fat absorption in infants. J. Pediatr. 125:S62-S68. https://doi.org/10.1016/S0022-3476(06)80738-9.

Lindmark Månsson, H. 2008. Fatty acids in bovine milk fat. Food Nutr. Res. 52:1821. https://doi.org/10.3402/fnr.v52i0.1821.

Mann, S., F. A. Leal Yepes, T. R. Overton, A. L. Lock, S. V. Lamb, J. J. Wakshlag, and D. V. Nydam. 2016. Effect of dry period dietary energy level in dairy cattle on volume, concentrations of immunoglobulin G, insulin, and fatty acid composition of colostrum. J. Dairy Sci. 99:1515-1526. https://doi.org/10.3168/jds.2015-9926.

Marounek, M., L. Pavlata, L. Mišurová, Z. Volek, and R. Dvorák. 2012. Changes in the composition of goat colostrum and milk fatty acids during the first month of lactation. Czech J. Anim. Sci. 57:28-33. https://doi.org/10.17221/5481-CJAS.

McDonnell, R. P., J. V. O'Doherty, B. Earley, A. M. Clarke, and D. A. Kenny. 2019. Effect of supplementation with n-3 polyunsaturated fatty acids and/or $\beta$-glucans on performance, feeding behaviour and immune status of Holstein Friesian bull calves during the pre- and post-weaning periods. J. Anim. Sci. Biotechnol. 10:7-24. https://doi.org/10.1186/s40104-019-0317-x.

McFadden, J. W., and B. A. Corl. 2009. Activation of AMP-activated protein kinase (AMPK) inhibits fatty acid synthesis in bovine mammary epithelial cells. Biochem. Biophys. Res. Commun. 390:388-393. https://doi.org/10.1016/j.bbrc.2009.09.017.

Medzhitov, R. 2010. Inflammation 2010: New adventures of an old flame. Cell 140:771-776. https://doi.org/10.1016/j.cell.2010.03 .006 .

Meydani, S. N. 1996. Effect of (n-3) polyunsaturated fatty acids on cytokine production and their biologic function. Nutrition 12(Suppl. 1):S8-S14. https://doi.org/10.1016/0899-9007(95)00082-8.

Miller, N., L. Delbecchi, D. Petitclerc, G. F. Wagner, B. G. Talbot, and P. Lacasse. 2006. Effect of stage of lactation and parity on mammary gland cell renewal. J. Dairy Sci. 89:4669-4677. https:// doi.org/10.3168/jds.S0022-0302(06)72517-6.

Moate, P. J., W. Chalupa, R. C. Boston, and I. J. Lean. 2007. Milk fatty acids. I. Variation in the concentration of individual fatty acids in bovine milk. J. Dairy Sci. 90:4730-4739. https://doi.org/ $10.3168 /$ jds.2007-0225.

Moltó-Puigmartí, C., A. I. Castellote, X. Carbonell-Estrany, and M. C. López-Sabater. 2011. Differences in fat content and fatty acid proportions among colostrum, transitional, and mature milk from women delivering very preterm, preterm, and term infants. Clin. Nutr. 30:116-123. https://doi.org/10.1016/j.clnu.2010.07.013.

Nicolaides, N., and T. Ray. 1965. Skin lipids. III. Fatty chains in skin lipids. The use of vernix caseosa to differentiate between endogenous and exogenous components in human skin surface lipid. J. Am. Oil Chem. Soc. 42:702-707. https://doi.org/10.1007/ BF02540043.

Nissen, A., P. H. Andersen, E. Bendixen, K. L. Ingvartsen, and C. M. Røntved. 2017. Colostrum and milk protein rankings and ratios of importance to neonatal calf health using a proteomics approach. J. Dairy Sci. 100:2711-2728. https://doi.org/10.3168/jds.2016-11722.

Noble, R. C., J. H. Shand, J. T. Drummond, and J. H. Moore. 1978 "Protected" polyunsaturated fatty acid in the diet of the ewe and the essential fatty acid status of the neonatal lamb. J. Nutr. 108:1868-1876. https://doi.org/10.1093/jn/108.11.1868.
Norman, J. E., S. Bollapragada, M. Yuan, and S. M. Nelson. 2007. Inflammatory pathways in the mechanism of parturition. BMC Pregnancy Childbirth 7(Suppl. 1):S7-S10. https://doi.org/10 .1186/1471-2393-7-S1-S7.

O'Callaghan, T. F., M. O'Donovan, J. P. Murphy, K. Sugrue, D. Mannion, W. P. McCarthy, M. Timlin, K. N. Kilcawley, R. M. Hickey, and J. T. Tobin. 2020. Evolution of the bovine milk fatty acid profile-From colostrum to milk five days post parturition. Int. Dairy J. 104:104655. https://doi.org/10.1016/j.idairyj.2020.104655.

Opgenorth, J., L. M. Sordillo, A. L. Lock, J. C. Gandy, and M. J. VandeHaar. 2020b. Colostrum supplementation with n-3 fatty acids alters plasma polyunsaturated fatty acids and inflammatory mediators in newborn calves. J. Dairy Sci. 103:11676-11688. https: //doi.org/10.3168/jds.2019-18045.

Opgenorth, J., L. M. Sordillo, and M. J. VandeHaar. 2020a. Colostrum supplementation with n-3 fatty acids and $\alpha$-tocopherol alters plasma polyunsaturated fatty acid profile and decreases an indicator of oxidative stress in newborn calves. J. Dairy Sci. 103:3545-3553. https://doi.org/10.3168/jds.2019-17380.

OriginLab Corp. 2021. OriginPro, Version Number 2021. OriginLab Corporation.

Paszczyk, B., Z. Zegarska, and Z. Borejszo. 2005. The contents of trans fatty acids and CLA in cow colostrums and milk fat in the early lactation period. Czech J. Food Sci. 23:159-165. https://doi.org/ 10.17221/3386-CJFS.

Poulsen, N. A., F. Gustavsson, M. Glantz, M. Paulsson, L. B. Larsen, and M. K. Larsen. 2012. The influence of feed and herd on fatty acid composition in 3 dairy breeds (Danish Holstein, Danish Jersey, and Swedish Red). J. Dairy Sci. 95:6362-6371. https://doi .org $/ 10.3168 /$ jds.2012-5820.

Ramiro-Cortijo, D., P. Singh, Y. Liu, E. Medina-Morales, W. Yakah, S. D. Freedman, and C. R. Martin. 2020. Breast milk lipids and fatty acids in regulating neonatal intestinal development and protecting against intestinal injury. Nutrients 12:534. https://doi.org/ 10.3390/nu12020534

Ran-Ressler, R. R., S. Bae, P. Lawrence, D. H. Wang, and J. Thomas Brenna. 2014. Branched-chain fatty acid content of foods and estimated intake in the USA. Br. J. Nutr. 112:565-572. https://doi .org/10.1017/S0007114514001081.

Ran-Ressler, R. R., S. Devapatla, P. Lawrence, and J. T. Brenna. 2008. Branched chain fatty acids are constituents of the normal healthy newborn gastrointestinal tract. Pediatr. Res. 64:605-609. https://doi.org/10.1203/PDR.0b013e318184d2e6.

Ran-Ressler, R. R., L. Khailova, K. M. Arganbright, C. K. AdkinsRieck, Z. E. Jouni, O. Koren, R. E. Ley, J. T. Brenna, and B. Dvorak. 2011. Branched chain fatty acids reduce the incidence of necrotizing enterocolitis and alter gastrointestinal microbial ecology in a neonatal rat model. PLoS One 6:e29032. https://doi.org/ 10.1371/journal.pone.0029032.

Rico, J. E., A. T. Mathews, J. Lovett, N. J. Haughey, and J. W. McFadden. 2016. Palmitic acid feeding increases ceramide supply in association with increased milk yield, circulating nonesterified fatty acids, and adipose tissue responsiveness to a glucose challenge. J. Dairy Sci. 99:8817-8830. https://doi.org/10.3168/jds .2016-11296.

Ringnér, M. 2008. What is principal component analysis? Nat. Biotechnol. 26:303-304. https://doi.org/10.1038/nbt0308-303.

Rouillé, B., and M. Montourcy. 2010. Influence of French dairy feeding systems on cow milk fatty acid composition. Grassl. Sci. Eur. 15:619-621.

Sanders, T. A. B., and D. J. Naismith. 1979. A comparison of the influence of breast-feeding and bottle-feeding on the fatty acid composition of the erythrocytes. Br. J. Nutr. 41:619-623. https:// doi.org/10.1079/BJN19790077.

Sardesai, V. M. 1992. Nutritional role of polyunsaturated fatty acids. J. Nutr. Biochem. 3:154-166. https://doi.org/10.1016/0955 $-2863(92) 90110-5$.

SAS Institute Inc. 2018. SAS 9.4M6, SAS Studio User's Guide. SAS Institute Inc. 
Schmitz, G., and J. Ecker. 2008. The opposing effects of n-3 and n-6 fatty acids. Prog. Lipid Res. 47:147-155. https://doi.org/10.1016/ j.plipres.2007.12.004.

Sherman, D. J., M. G. Ross, L. Day, and M. G. Ervin. 1990. Fetal swallowing: Correlation of electromyography and esophageal fluid flow. Am. J. Physiol. 258:R1386-R1394. https://doi.org/10.1152/ ajpregu.1990.258.6.R1386.

Smith, S. L., and C. A. Rouse. 2017. Docosahexaenoic acid and the preterm infant. Matern. Health Neonatol. Perinatol. 3:22. https:// doi.org/10.1186/s40748-017-0061-1.

Stockdale, C. R., G. P. Walker, W. J. Wales, D. E. Dalley, A. Birkett, Z. Shen, and P. T. Doyle. 2003. Influence of pasture and concentrates in the diet of grazing dairy cows on the fatty acid composition of milk. J. Dairy Res. 70:267-276. https://doi.org/10.1017/ S0022029903006009.

Sun, C., X. Zou, Y. Yao, J. Jin, Y. Xia, J. Huang, Q. Jin, and X. Wang. 2018. Evaluation of fatty acid composition in commercial infant formulas on the Chinese market: A comparative study based on fat source and stage. Int. Dairy J. 63:42-51. https://doi.org/10 .1016/j.idairyj.2016.07.015.

Taylor, M. W., and A. K. H. MacGibbon. 2002. Triaglycerols, Vol. 3. Elsevier Science Ltd.

van Niekerk, J. K., A. J. Fischer-Tlustos, J. N. Wilms, K. S. Hare, A. C. Welboren, A. J. Lopez, T. T. Yohe, L. R. Cangiano, L. N. Leal, and M. A. Steele. 2021. ADSA Foundation Scholar Award: New frontiers in calf and heifer nutrition: From conception to pu- berty. J. Dairy Sci. 104:8341-8362. https://doi.org/10.3168/jds .2020-20004.

Wiking, L., J. Stagsted, L. Björck, and J. H. Nielsen. 2004. Milk fat globule size is affected by fat production in dairy cows. Int. Dairy J. 14:909-913. https://doi.org/10.1016/j.idairyj.2004.03.005.

Wilms, J., K. Hare, A. J. Fischer-Tlustos, P. Vahmani, M. Dugan, L. Leal, and M. A. Steele. 2021. Wilms et al. 2022. FA characterization in colostrum, transition milk, and mature milk. Supplemental material.docx. figshare. Figure. https://doi.org/https://doi.org/10 $.6084 / \mathrm{m} 9$.figshare.17277938.v1

Wolff, R. L., C. C. Bayard, and R. J. Fabien. 1995. Evaluation of sequential methods for the determination of butterfat fatty acid composition with emphasis on trans-18:1 acids. Application to the study of seasonal variations in French butters. J. Am. Oil Chem. Soc. 72:1471-1483. https://doi.org/10.1007/BF02577840.

Woolpert, M. E., H. M. Dann, K. W. Cotanch, C. Melilli, L. E. Chase, R. J. Grant, and D. M. Barbano. 2017. Management practices, physically effective fiber, and ether extract are related to bulk tank milk de novo fatty acid concentration on Holstein dairy farms. J. Dairy Sci. 100:5097-5106. https://doi.org/10.3168/jds.2016-12046.

Xin, H., Y. Xu, Y. Chen, G. Chen, M. A. Steele, and L. L. Guan. 2020. Short communication: Odd-chain and branched-chain fatty acid concentrations in bovine colostrum and transition milk and their stability under heating and freezing treatments. J. Dairy Sci. 103:11483-11489. https://doi.org/10.3168/jds.2020-18994. 